\title{
Валерий Васильевич Козлов
}

\author{
К 60-летию
}

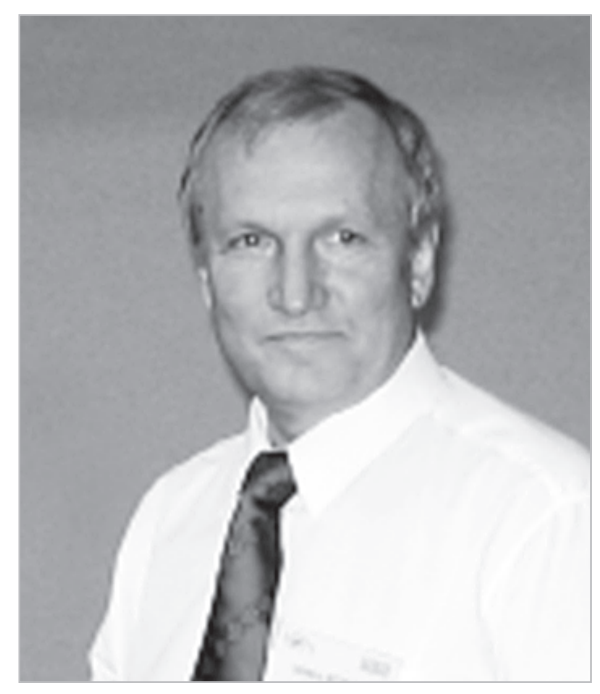

Валерий Васильевич Козлов родился в небольшой глухой деревушке в российской глубинке. Сейчас там уже никто не живет. В первый класс он пошел в местную сельскую школу, в которой была всего одна учительница. В первую смену она вела одновременно два класса - первый и третий, а во вторую смену (после обеда) - второй и четвертый.

Восьмилетним мальчиком В. В. вместе с родителями переехал в подмосковный городок Люблино-Дачное. После строительства окружной автодороги это место оказалось внутри расширившейся Москвы. Так В. В. стал москвичом.

По рассказам В.В., он не любил школу, но учился легко. В двух последних классах он серьезно увлекся математикой и физикой, по вечерам ездил на занятия в физико-математическую школу при МВТУ им. Баумана. Там он познакомился и подружился с А. Нейштадтом. Кстати сказать, всего четверо выпускников этой школы сдали все выпускные экзамены на «отлично». Среди них - В. Козлов и А. Нейштадт.

В. В. окончил школу с золотой медалью и поступил на механико-математический факультет Московского университета. Он решил все задачи письменного экзамена по математике, что удалось только 7 абитуриентам из 450 поступивших.

Первый по-настоящему крупный научный результат был получен В. В. уже на четвертом курсе. Он решил поставленную Пуанкаре проблему о неинтегрируемости уравнений движения тяжелого несимметричного волчка. Пуанкаре обсуждал эту задачу в первом томе своих знаменитых «Новых методов небесной механики», связывая ее с исследованием С. Ковалевской.

На пятом курсе В. В. «доводил» эту тему. В итоге его дипломная работа была опубликована в четырех статьях. Затем В. В. исследовал условия расщепления сепаратрис при возмущении задачи Эйлера-Пуансо и связал этот круг вопросов с ветвлением решений в плоскости комплексного времени. Последний результат является решением старой проблемы

НЕЛИНЕЙНАЯ ДИНАМИКА, 2010, Т. 6, № 3, с. 461-473 


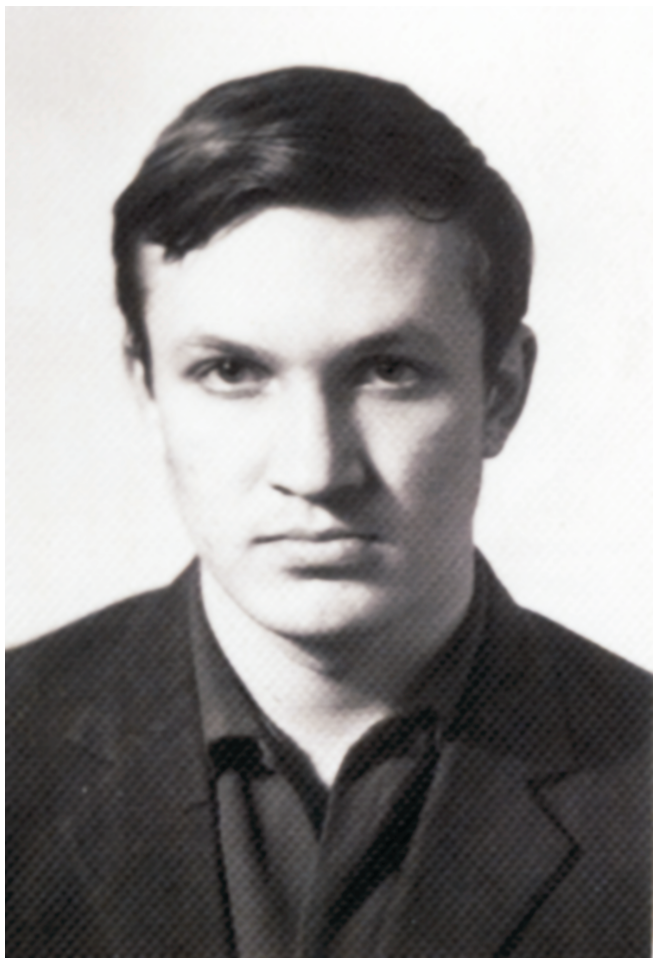

Студент 4-го курса механико-математического факультета МГУ им. М. В. Ломоносова (1971)

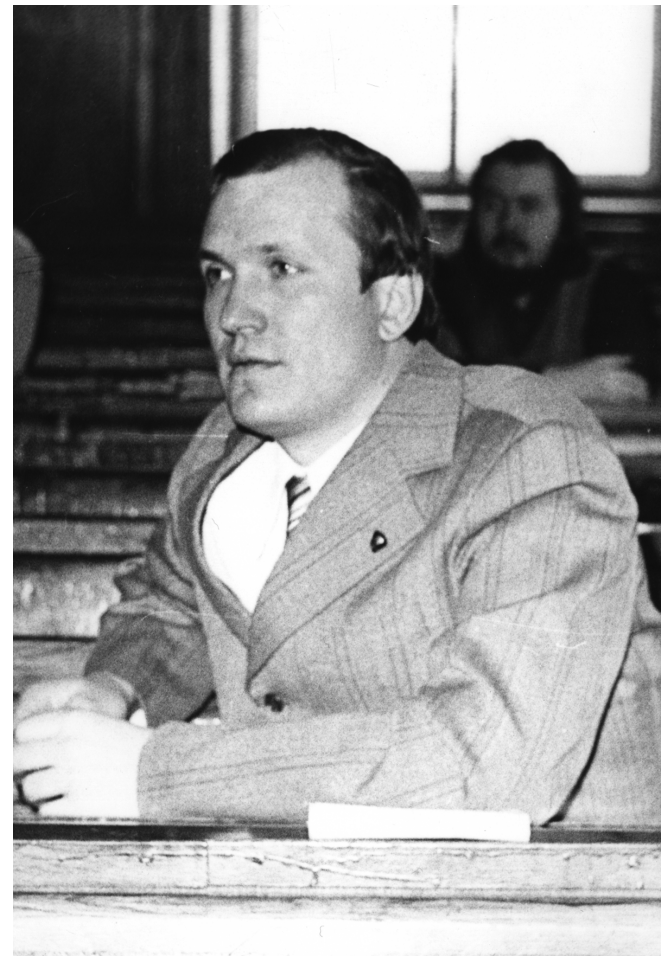

Лауреат премии Ленинского комсомола (1977)

Пенлеве-Голубева. За эти достижения 27-летнему В.В. присудили премию Ленинского комсомола - высшую научную награду в СССР для молодых ученых. Как говорится, В. В. «проснулся знаменитым»: после присуждения премии он сразу получил известность. В 28 лет защитил докторскую диссертацию, основу которой составили его яркие результаты по динамике несимметричного волчка.

Достижения В.В.Козлова были развиты и дополнены С. Зиглиным, статьи которого часто цитируются. Примерно в то же время В.В. открыл топологические препятствия к интегрируемости, доказав отсутствие аналитического первого интеграла геодезических потоков на поверхностях рода $g \geqslant 2$ (или, что то же самое, с отрицательной эйлеровой характеристикой). Как сказал Джон Хорнстейн (John Hornstein), «Here is an example of how differential geometry, differential and algebraic topology, and Newton's laws make music together».

Эта статья была представлена в Доклады Академии наук А.Н. Колмогоровым, работы которого по динамическим системам оказали на В. В. большое влияние. Теорема В.В. о топологических препятствиях развивалась в работах И. Тайманова, Г. Паттернайна, С. Болотина и др.

Говоря о проблеме интегрируемости гамильтоновых систем, упомянем еще работы В. В., сделанные вместе с его учеником Д. Трещёвым. В частности, ими получено решение задачи о классификации вполне интегрируемых систем с экспоненциальным взаимодействием (сюда относятся цепочки Тоды и их обобщения). Это - трудная работа в техническом отношении. Классификация выражена в терминах оснащенных графов Кокстера для «спектра» потенциальной энергии. Упомянем еще открытую В. В. очень загадочную связь между 
степенями неприводимых полиномиальных по импульсам первых интегралов с топологией конфигурационного пространства. Все эти замечательные результаты были предметом его приглашенного доклада на Международном конгрессе математиков в Беркли (США, 1986).

Возвращаясь немного назад, стоит упомянуть, что он пробыл в аспирантуре всего год и защитил кандидатскую диссертацию по совершенно другой теме. Он дал качественный анализ вращения волчка Ковалевской. Развитые в его диссертации методы, к сожалению, освоены еще не в полной мере.

Параллельно с исследованиями по несимметричному волчку В. В. выполнил работы по вариационным методам. Он доказал существование либрационных периодических траекторий в областях возможности движения с несвязной границей. Либрации имеют с границей ровно две общие точки, и в этих положениях скорость системы обращается в нуль. В. В. не знал о подзабытой работе знаменитого тополога Г. Зейферта 1948 года, в которой, правда, был рассмотрен в определенном смысле противоположный случай, когда область возможности движения диффеоморфна шару. Затем В. В. вместе с С. Болотиным дали оценки снизу числа либраций через топологию области возможности движения. В. В. доказал также фундаментальную теорему о попадании на границу, играющую важную роль в задачах изоэнергетического импульсного управления. За работы по вариационным методам В. В. была присуждена Ломоносовская премия І-й степени - высшая научная награда Московского университета (1986 г.).

В 1980-х годах В.В. обратился к теории устойчивости. Он поставил перед собой амбициозную задачу - доказать обратную теорему Лагранжа-Дирихле для аналитических потенциалов. Это знаменитая гипотеза Ляпунова. Для этой цели В. В. развил первый метод Ляпунова для сильно нелинейных систем, когда асимптотически исходящие решения ищутся в виде ряда по обратным дробным степеням времени, а коэффициенты рядов - многочлены от логарифмов времени. В 1982 году В. В. получил первый нетривиальный результат по проблеме обращения теоремы Лагранжа-Дирихле. Из него, в частности, вытекало, что все равновесия в поле с гармоническим потенциалом неустойчивы. Тем самым было впервые дано полное и строгое доказательство знаменитой теоремы Ирншоу о неустойчивости равновесий системы зарядов в электростатическом силовом поле, высказанной еще в 1839 году. Этот выдающийся результат сразу выдвинул В. В. в число ведущих специалистов по теории устойчивости.

В разработку первого метода Ляпунова для сильно нелинейных систем В. В. «вовлек» В. Паламодова и его ученика А. Кузнецова. Кстати сказать, А. Кузнецов получил в этой области фундаментальный результат: если ряд по обратным степеням времени с логарифмами (включая повторные) расходится, то он все равно будет асимптотическим рядом для некоторого настоящего решения автономной системы дифференциальных уравнений.

Упомянем еще работу В. В., в которой решена задача об устойчивости равновесия неавтономной системы, когда потенциальная энергия умножается на заданную неограниченную функцию времени. Уравнения такого типа описывают, например, вращение тяжелого твердого тела, падающего в бесконечном объеме идеальной жидкости. В этом случае множитель - квадратный многочлен от времени. Характерная (и удивительная) особенность таких систем состоит в том, что амплитуда колебаний стремится к нулю, а частота, наоборот, неограниченно возрастает.

В связи с этим результатом упомянем одну любопытную историю. В 1989 году В. В. опубликовал работу, в которой дал полный качественный анализ задачи о падении тяжелого твердого тела в идеальной жидкости. В ней показано, что для почти всех начальных данных тело стремится занять такое положение, при котором его широкая сторона горизонтальна.

НЕЛИНЕЙНАЯ ДИНАМИКА, 2010, Т. 6, № 3, с. 461-473 


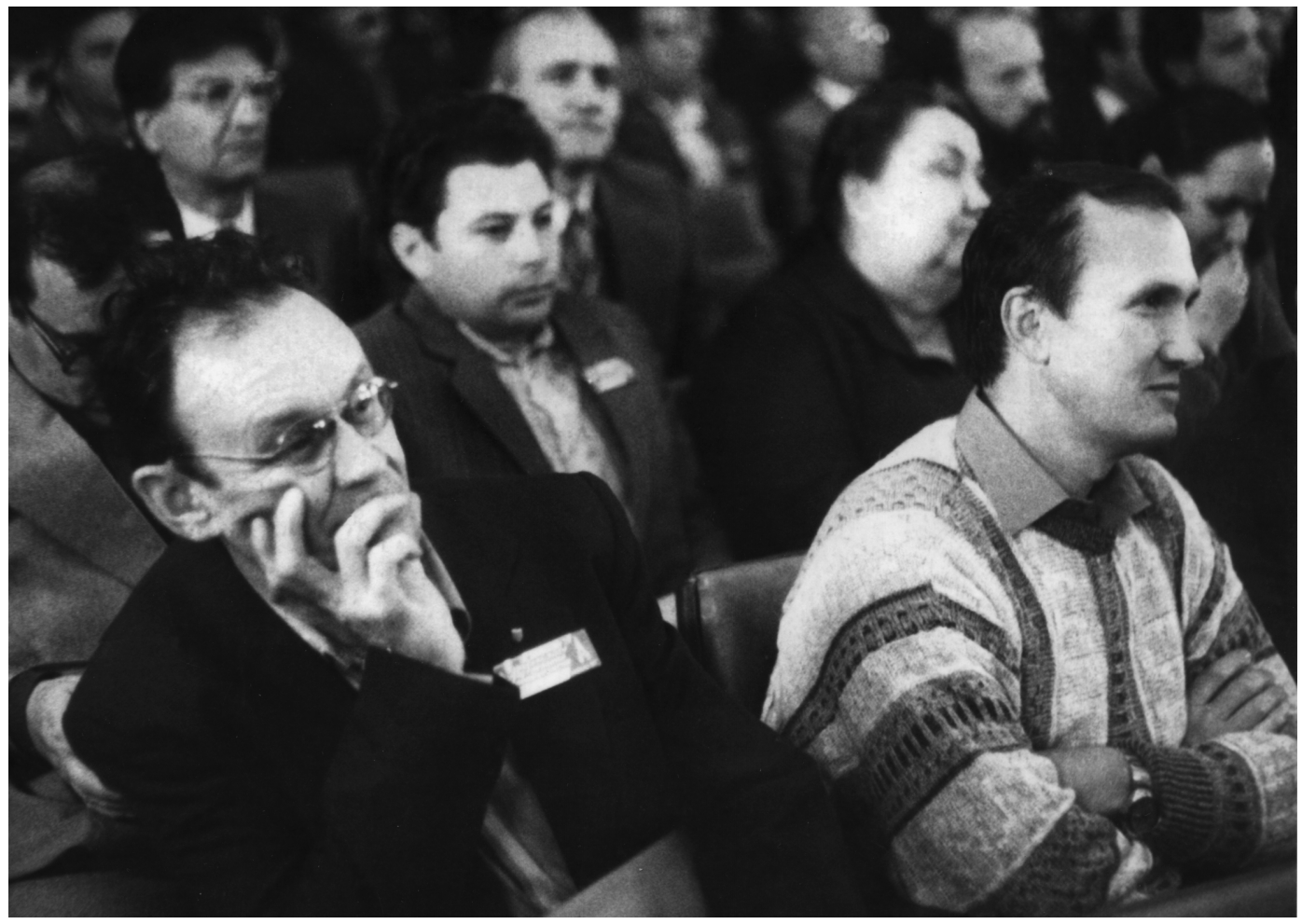

На Четаевской конференции (1983)

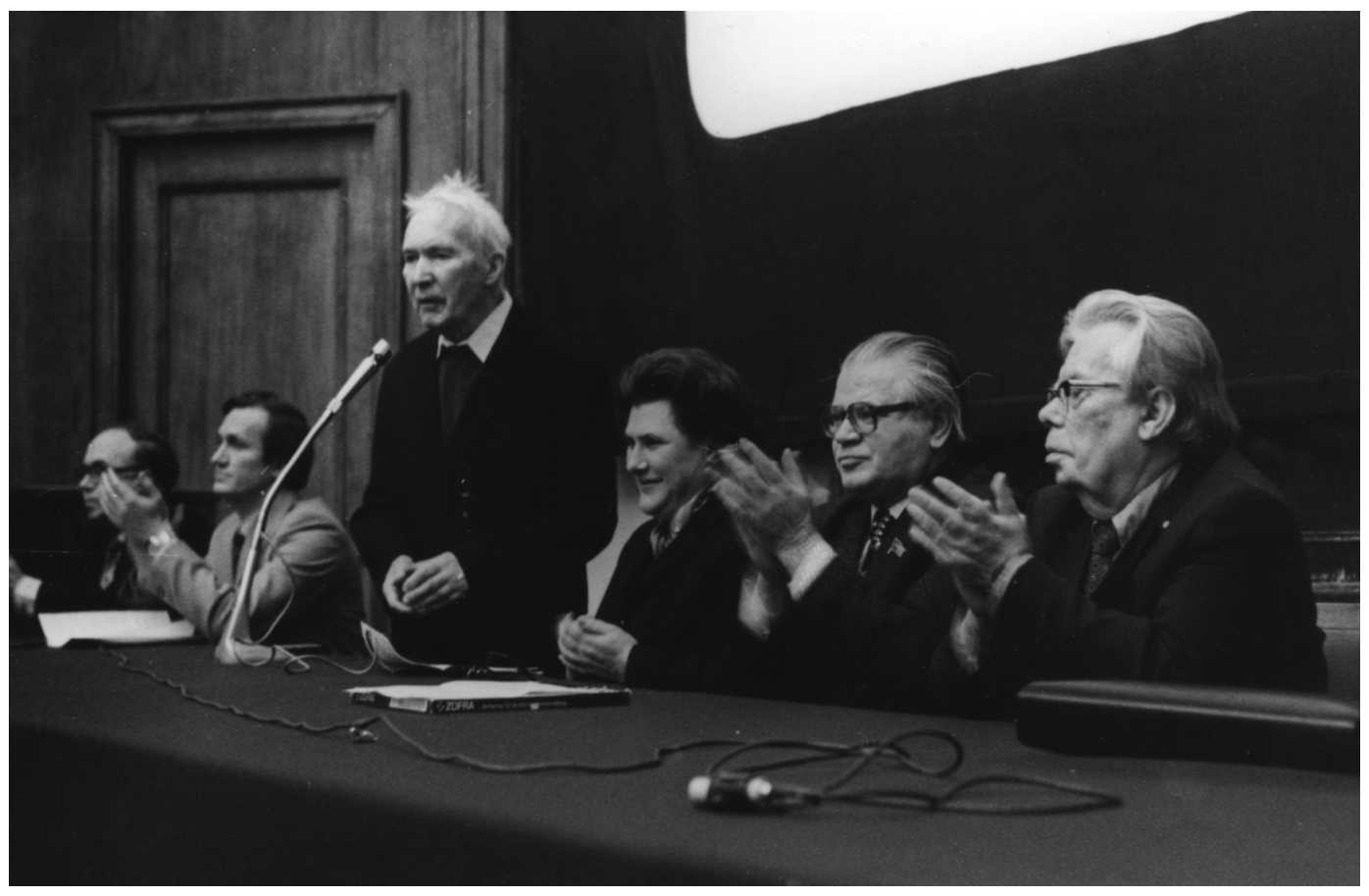

В. В. Козлов, А. Н. Колмогоров, О. А. Олейник, А. А. Логунов,

Н. Н. Боголюбов на открытии конференции им. И. Г. Петровского (1985) 
Приближаясь к этому положению, тело совершает угловые колебания с убывающей амплитудой и возрастающей частотой. Исключение составляют движения, при которых твердое тело асимптотически падает узкой стороной вперед; все они неустойчивы.

В. В. считал, что эта задача впервые была рассмотрена в студенческой работе С. А. Чаплыгина 1890 года. Однако она не была сразу опубликована, поскольку Чаплыгину не удалось проинтегрировать уравнения движения и он счел свое исследование неполным. Правда, С. А. Чаплыгин все же поместил ее в свое собрание сочинений 1932 года.

На самом же деле (как мы потом выяснили) еще в 1889 году появилась обширная работа В.А.Стеклова на эту тему. В ней он пытался доказать сформулированное выше свойство падающего тела в жидкости. Однако ему это не удалось. Об этом он сам пишет в одной из своих последующих публикаций с упоминанием критических замечаний его учителя А. М. Ляпунова. Кстати сказать, в библиотеке МИАН мы нашли экземпляр книги В. А. Стеклова на эту тему с множеством пометок Ляпунова. Таким образом, В. В. решил задачу, с которой так и не справился В. А. Стеклов.

Упомянем еще о цикле работ В. В. по теории гироскопической стабилизации. Казалось бы, это избитая тема, относящаяся к теории линейных систем, и вряд ли что сюда можно добавить. Однако это далеко от истины. В.В. преобразовал теорию гироскопической стабилизации, обогатив ее новыми идеями симплектической геометрии, топологии и спектральной теории.

Bсе, к чему прикасается В. В., начинает играть новыми красками. Вот простой, но поучительный пример. Как обнаружил В. В., любая линейная автономная система с изолированным равновесием, допускающая интеграл в виде невырожденной квадратичной формы, обязательно гамильтонова. В частности, ее фазовое пространство имеет четную размерность. Более того, гамильтонианом служит именно этот квадратичный интеграл. Читатель сам может попытаться найти соответствующую симплектическую структуру.

Еще одна характерная черта творчества В. В. - параллельная работа сразу над несколькими различными темами. В 1982 году вместе с публикациями по первому методу Ляпунова для сильно нелинейных систем вышли первые статьи В. В. по реализации связей в системах с анизотропией тензора инерции.

Для разрешения известных парадоксов Пенлеве о движении твердых тел с сухим трением, Прандтлем, Клейном, Лекорню предложено заменить твердые тела (т. е. наложенные на систему голономные связи) упругими телами с большим коэффициентом упругости. Общая теорема о реализации голономных связей потенциальным силовым полем сформулирована позже Курантом. Кстати сказать, ее доказательство в общем случае было дано в работе В.В.и А. Нейштадта (1990 г.).

Сходная идея о реализации неголономных связей силами анизотропного вязкого трения была высказана К. Каратеодори и развита Н. Фуфаевым, И. Новожиловым, А. Бренделевым и А. Карапетяном.

В.В. предложил новый способ реализации неинтегрируемых связей путем введения анизотропии в инерционные свойства системы. Хорошее представление о такой анизотропии дает движение пластинки в жидкости: при движении острой кромкой вперед пластинка вообще не «чувствует» идеальную жидкость, а при движении широкой стороной вперед к ее массе добавляется присоединенная масса жидкости.

В.В. доказал общую теорему о предельном переходе в лагранжевых уравнениях движения с анизотропией тензора инерции, в результате которого предельные движения удовлетворяют не уже привычным неголономным уравнениям, а являются экстремалями вари-

НЕЛИНЕЙНАЯ ДИНАМИКА, 2010, Т. 6, № 3, с. 461-473 


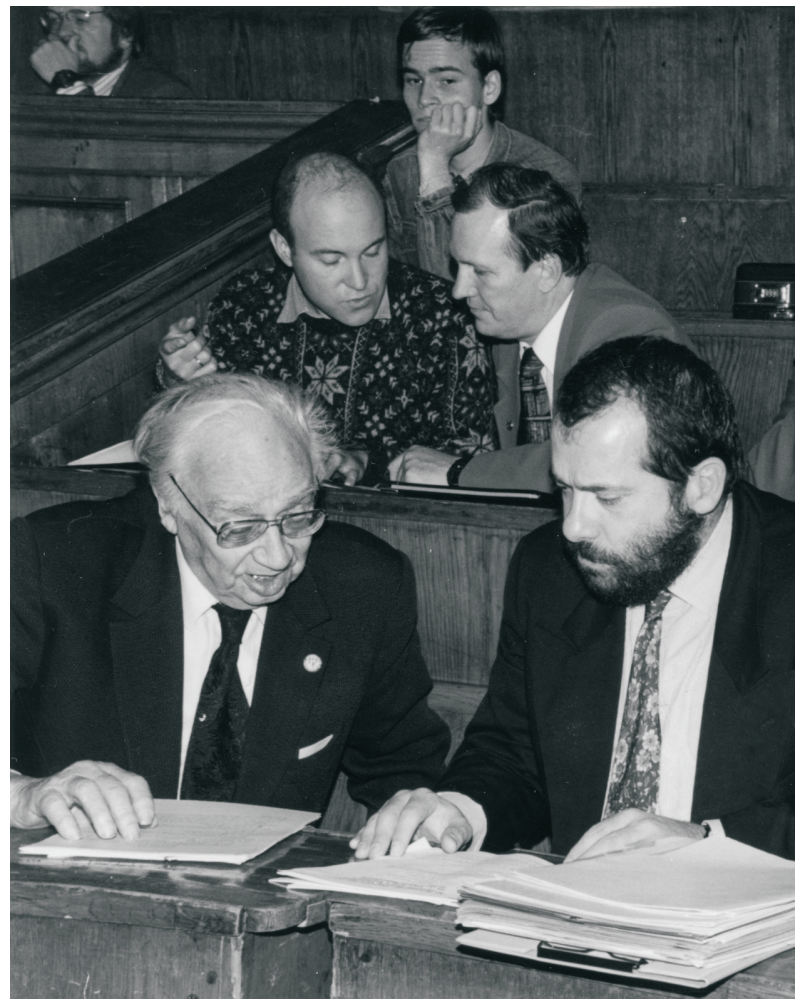

С. Д. Фурта, В.В.Козлов, Л. И. Седов, И. Антониу (1993)

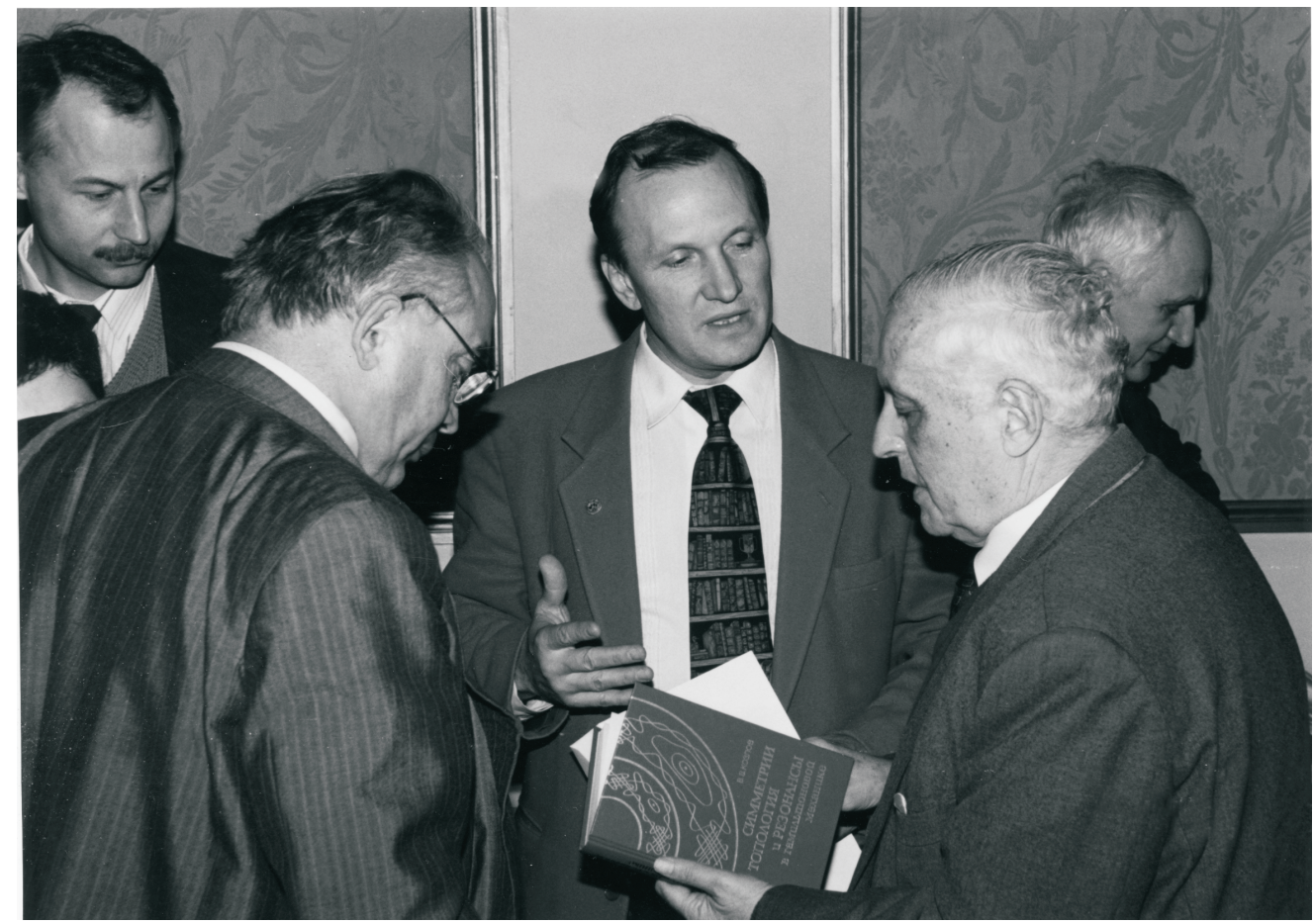

В. В. Белокуров, В. А. Садовничий, В. В. Козлов, И. Пригожин, В. А. Ильин (1995) 
ационной задачи Лагранжа с неинтегрируемыми ограничениями. До работ В. В. задача Лагранжа не связывалась с описанием движения реальных механических систем со связями.

Вариационную модель движения систем со связями теперь принято называть вакономной механикой. Для интегрируемых связей она дает классические уравнения движения голономных систем.

Добавляя анизотропное трение и переходя к пределу в уравнениях движения, В. В. получил обобщенную модель движения систем с неинтегрируемыми связями, зависящую от параметра. На одном конце интервала возможных значений этого параметра мы имеем обычную неголономную механику, а на другом - новую вакономную механику. В реальной ситуации выбор модели в конечном счете решает эксперимент. Например, как показал В.В., движение узких продолговатых пластинок в жидкости с малой вязкостью хорошо описывается уравнениями вакономной механики.

В.В. развил аналитическую динамику систем со связями в рамках обобщенной модели. Не каждому дано открыть новый тип уравнений движения и первому исследовать их основные свойства. Эти работы В.В. вполне сопоставимы с исследованиями знаменитых классиков и являются их прямым продолжением.

Цикл работ В.В. по динамике систем с неинтегрируемыми связями удостоен премии АН СССР им. С. А. Чаплыгина (1988 г.).

Сразу вслед за этим В.В. опубликовал работы по реализации односторонних связей, когда «запрещенное» для движения полупространство заменяется средой Кельвина-Фойгта, а затем коэффициенты упругости и трения некоторым согласованным образом устремляются к бесконечности. В итоге получается целое семейство физически ясных моделей движения систем с односторонними связями. Они описывают как явление схода со связи, так и явление удара. При существенном трении получаем модель неупругого удара, а при отсутствии трения имеем абсолютно упругий удар. Основываясь на этих общих результатах, В.В. развил новый подход к исследованию устойчивости движений с ударами. Все это является выдающимся вкладом в теорию систем со связями.

Еще один цикл работ В.В., начатый почти в то же время (1983г.), можно назвать «гидродинамикой гамильтоновых систем». Полученные результаты подытожены в ярко написанной монографии «Общая теория вихрей» (1998г.). Речь идет об открытии глубоких аналогий между гамильтоновыми системами, гидродинамикой идеальной жидкости, системами лучей из геометрической оптики и адиабатическими процессами из равновесной термодинамики. Как показал В. В., все эти объекты описываются одним уравнением

$$
\frac{\partial \omega}{\partial t}+i_{v} d \omega=-d h
$$

Здесь $\omega-1$-форма, $v$ - векторное поле, а $h-$ функция, заданные на конфигурационном пространстве; все эти объекты могут еще явно зависеть от времени. В случае адиабатических процессов роль времени играет температура.

Один из основных объектов теории В.В. - это инвариантные многообразия гамильтоновых систем, которые однозначно проектируются на конфигурационное пространство. Проекция гамильтонова векторного поля на конфигурационное пространство удовлетворяет многомерным уравнениям Ламба из гидродинамики. В итоге имеем поток на конфигурационном пространстве, задаваемый дифференциальным уравнением первого (а не второго) порядка. В памяти воскрешаются идеи вихревой теории Декарта, отвергнутой (и напрасно!) ньютоновской механикой.

НЕЛИНЕЙНАЯ ДИНАМИКА, 2010, Т. 6, № 3, с. 461-473 


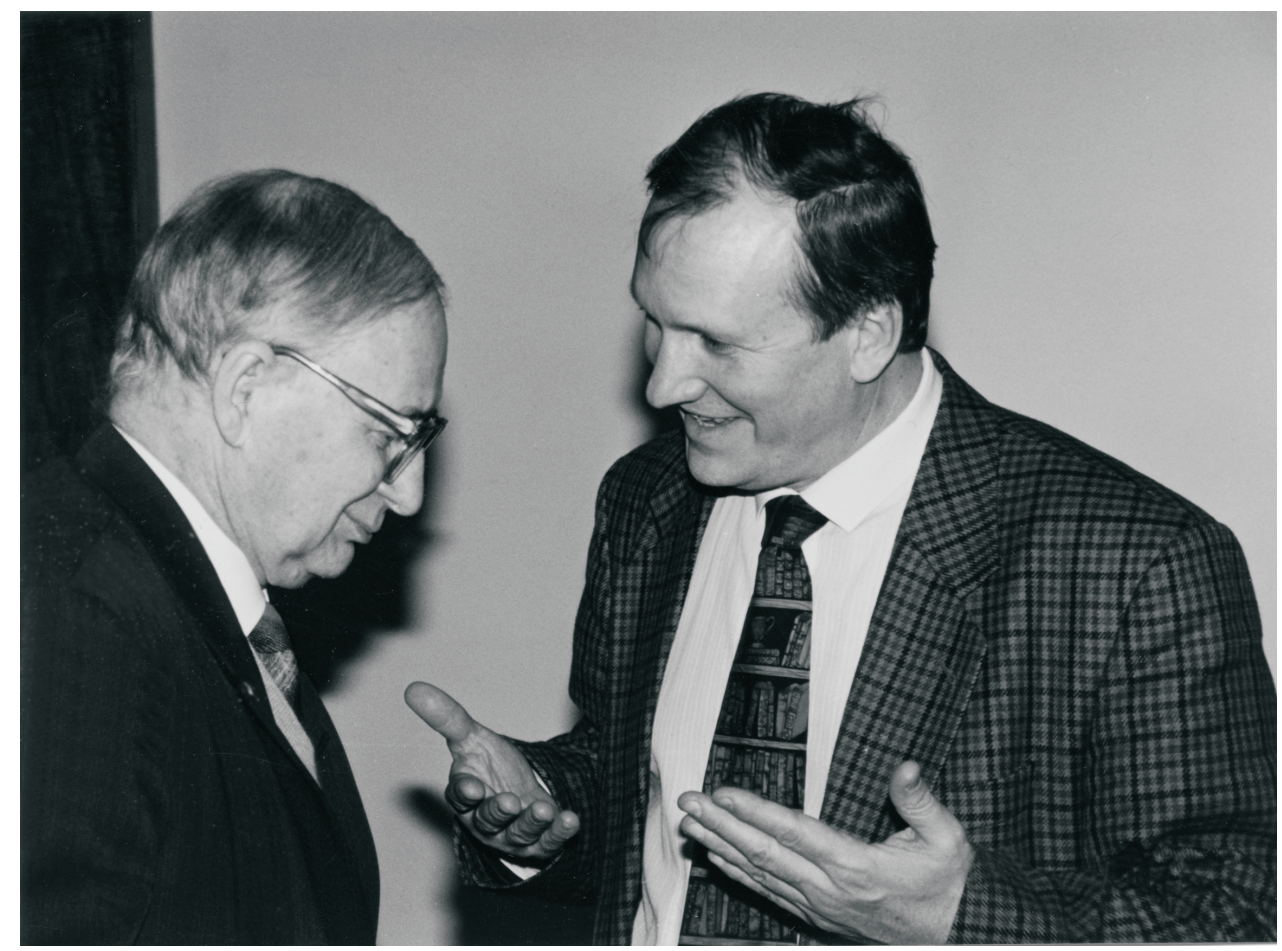

С академиком Д. Е. Охоцимским (1997)

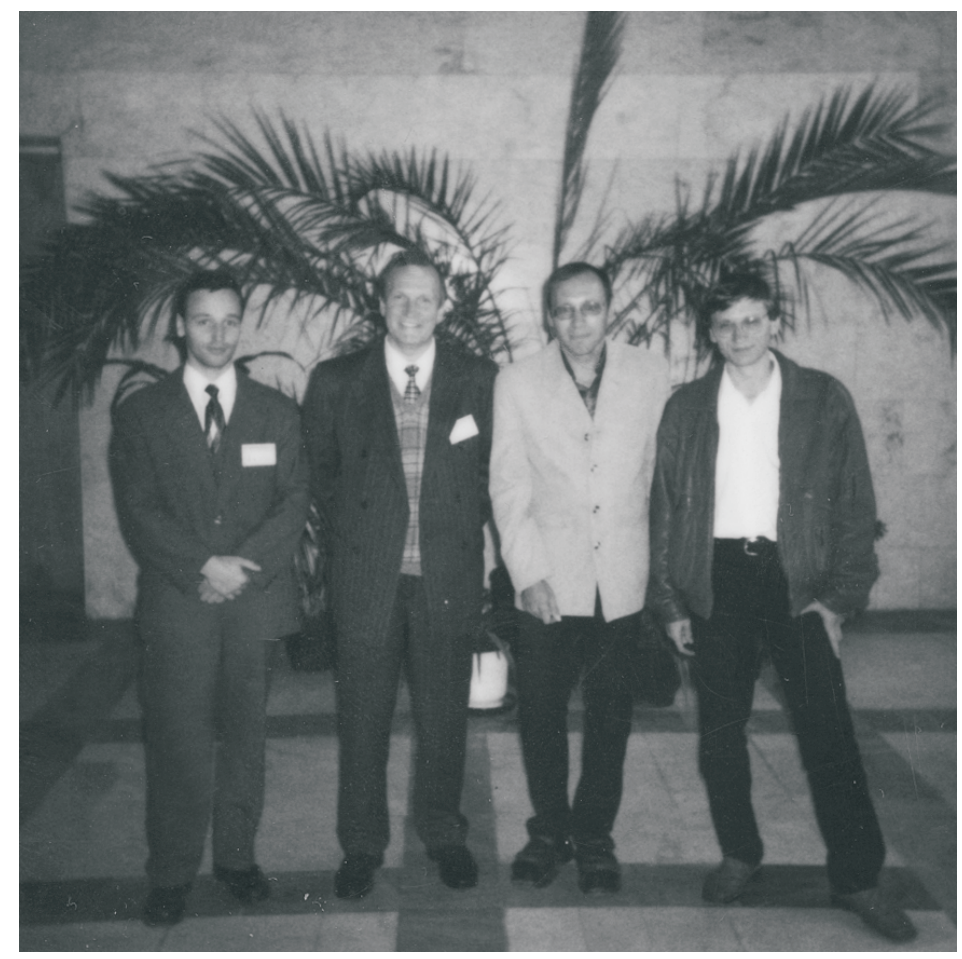

Пермь, Всероссийский съезд по теоретической и прикладной механике. С А. А. Килиным, А. В. Борисовым и И. С. Мамаевым (2000) 
Но откуда брать эти инвариантные поверхности? Вот одна из конструкций, предложенная В. В. Рассмотрим задачу о геодезических на группе Ли с левоинвариантной метрикой. Популярный пример - волчок Эйлера. Здесь группа Ли - это группа вращений трехмерного евклидова пространства, а левоинвариантная метрика - это кинетическая энергия волчка. Возьмем теперь любое правоинвариантное поле на группе Ли. Его фазовый поток состоит из левых сдвигов на группе. По теореме Нётер получаем первый интеграл движения, линейный по скоростям. Ясно, что количество функционально независимых нётеровых интегралов совпадает с размерностью группы Ли, которая служит пространством конфигураций. Фиксируя постоянные нётеровых интегралов, получаем искомую инвариантную поверхность.

Для волчка Эйлера это означает, что надо зафиксировать постоянные кинетического момента тела в проекции на оси неподвижного трехгранника. Как показал В. В., на группе $S O(3)$ возникает поток, по всем своим свойствам схожий с вихревым стационарным течением идеальной жидкости. Роль плотности такой воображаемой жидкости играет плотность биинвариантной меры Хаара.

Гидродинамический подход к изучению уравнений Гамильтона позволил В. В. развить общий вихревой метод их интегрирования. Он тесно связан с теорией некоммутативного интегрирования гамильтоновых систем. Для потенциальных (безвихревых) течений этот метод переходит в классический метод Гамильтона-Якоби.

С помощью описанной техники В.В. получил совершенно удивительный результат о движении тела в жидкости с твердой оболочкой, геометрия масс которого меняется за счет внутренних сил. Например, по внутренней поверхности оболочки ползет жук. Если бы жидкости не было, то центр масс тела был бы, конечно, неподвижен. А в жидкости все выглядит иначе. Как установил В.В., если не все присоединенные массы оболочки равны между собой, то за счет подходящего изменения геометрии масс оболочку тела можно переместить из любого положения в любое заданное. Разумеется, конечное положение тела может отстоять от начального сколь угодно далеко!

Еще один цикл работ В.В. связан с изучением тензорных инвариантов уравнений динамики. Кроме первых интегралов сюда относятся поля симметрий, инвариантные дифференциальные формы (и связанные с ними интегральные инварианты), инвариантные меры и т. Д. Локально, в окрестности неособой точки, всегда имеются инвариантные тензоры любой структуры. Ситуация резко меняется, когда инвариантные тензоры определены во всем фазовом пространстве или его части, где имеет место возвращаемость траекторий. По сути, до работ В. В. так задачу не ставили, и поэтому его работы носят пионерский характер.

Для квазиоднородных систем дифференциальных уравнений (сюда относятся уравнения Эйлера-Пуассона, уравнения задачи многих гравитирующих тел и др.) В. В. открыл резонансные соотношения на показатели Ковалевской, зависящие от структуры тензорного инварианта. Доказал, что уравнения геодезических на поверхности рода большего единицы не допускают нетривиальных полей симметрии и линейных интегральных инвариантов. В 1995 году В.В. решил задачу Пуанкаре о несуществовании новых линейных интегральных инвариантов ограниченной задачи трех тел, поставленную в III-м томе «Новых методов небесной механики».

Чтобы понять и оценить значение этих результатов, сравним их с известной теоремой Ли Хуа Чжуна о том, что все гамильтоновы системы на одном и том же фазовом пространстве допускают только следующий универсалъный интегральный инвариант

$$
c \int \sum p d q, \quad c=\text { const. }
$$

НЕЛИНЕЙНАЯ ДИНАМИКА, 2010, Т. 6, № 3, с. 461-473 


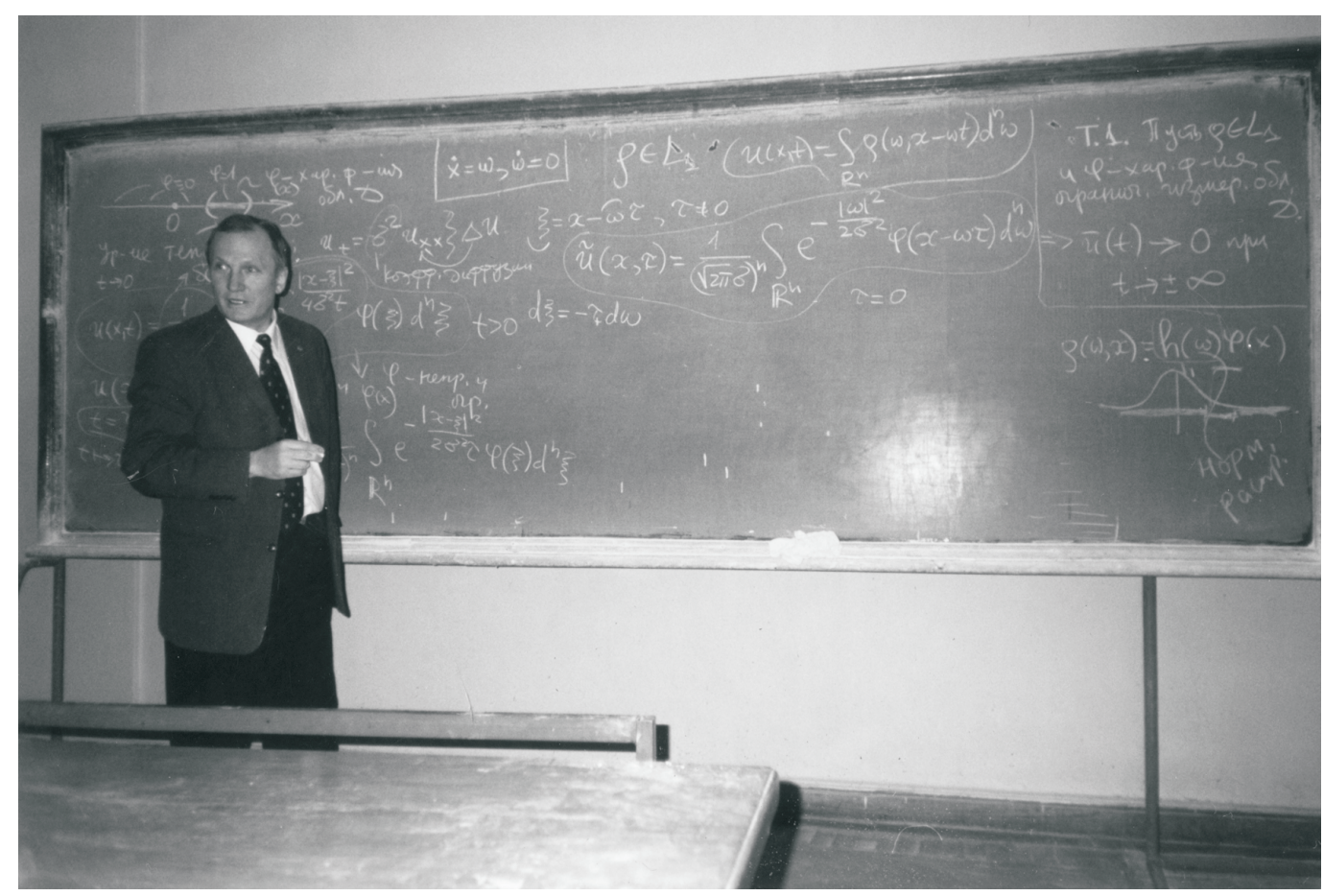

На семинаре в МГУ им. М. В. Ломоносова (2003)

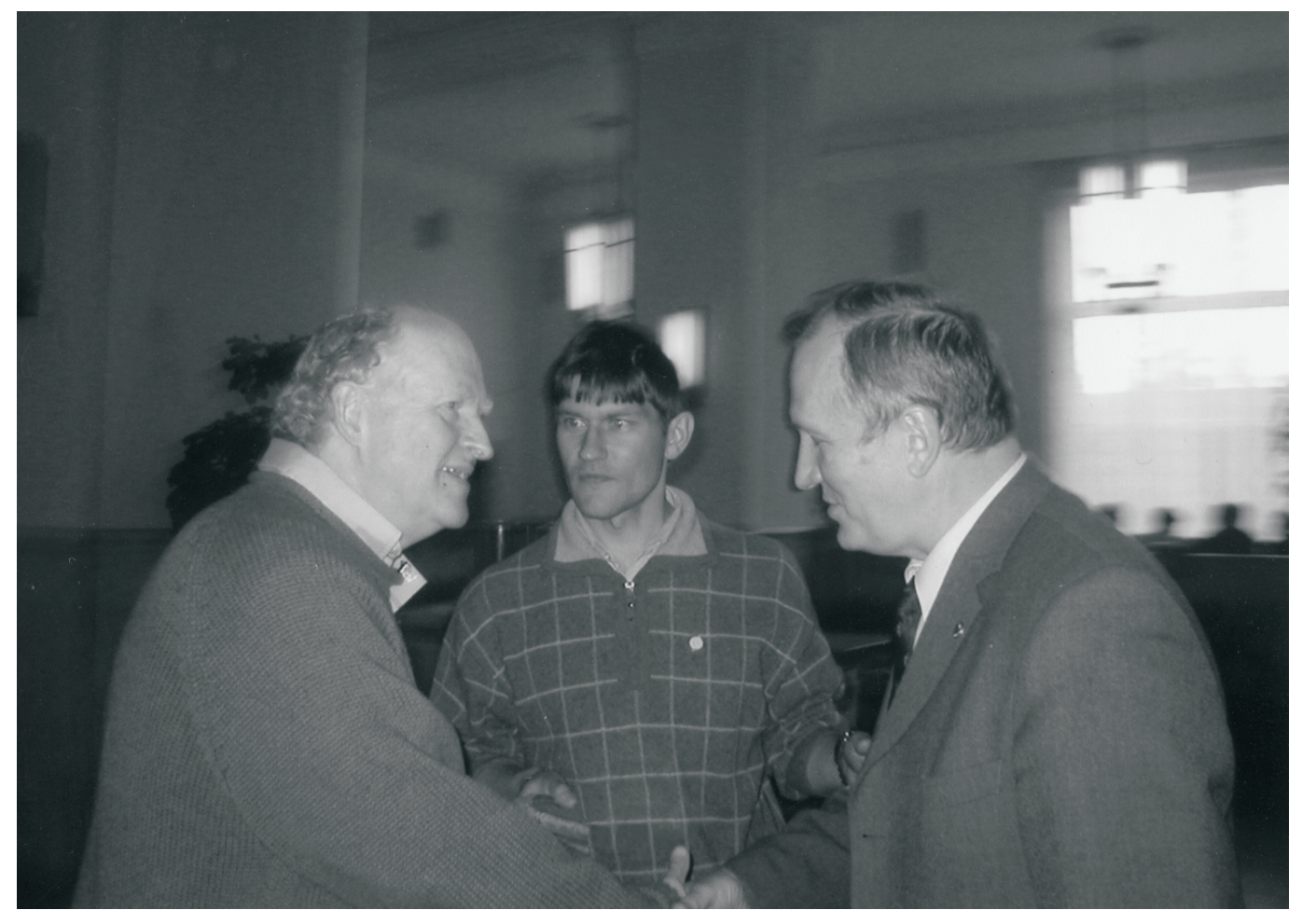

С Дж. Мезером и Д. В. Трещевым (2005) 
Эта теорема содержится во многих учебниках по классической механике. Согласно В.В., интегральные инварианты отделъных гамильтоновых систем со сложным поведением фазовых траекторий пропорциональны инварианту Пуанкаре-Картана, а множитель зависит лишь от функции Гамильтона.

В.В. обнаружил, что типичные неголономные системы не допускают инвариантной меры. Напомним, что голономные системы всегда имеют инвариантную меру Лиувилля. Таким образом, случаи наличия инвариантной меры для неголономных уравнений так же редки, как, скажем, случаи существования дополнительных интегралов для уравнений Гамильтона.

За работы по тензорным законам сохранения В. В. Козлов и С. В. Болотин были удостоены премии им. С. В. Ковалевской РАН (2000 г.).

В 1999 году В. В. стал заведующим кафедрой математической статистики и случайных процессов МГУ и сразу же переключился на «вероятностную» тематику. Он стал систематически заниматься статистической механикой, а также кругом вопросов, связанных с применением расходящихся рядов к теории равномерного распределения Г. Вейля и к обобщению и усилению закона больших чисел. По второй теме он опубликовал несколько оригинальных работ, в которых, в частности, усилил знаменитую теорему Вейля о равномерном распределении значений многочлена с иррациональным коэффициентом.

В.В. любит говорить, что статистическая механика - это механика, обогащенная вероятностными представлениями. Он очень много сделал для развития как равновесной, так и неравновесной статистической механики. В равновесном случае он дал вывод распределения Гиббса, не опирающийся на эргодическую теорию и применимый к системам с конечным числом степеней свободы.

Основное его достижение в неравновесной статмеханике - это математически корректное обоснование нулевого начала термодинамики в рамках теории ансамблей Гиббса. Он дал корректное решение проблемы обратимости, которая оказалась недоступной многим выдающимся исследователям. Центральное место в подходе В.В. занимает идея слабой сходимости решений уравнения Лиувилля. В неявном виде эта идея была использована А. Пуанкаре в его непонятой работе «Замечания о кинетической теории газов» (1906 г.).

Результат В. В. можно проиллюстрировать его уравнением

$$
u_{t}^{\prime}=t \sigma^{2} \Delta u, \quad \sigma^{2}=\text { const }
$$

которое описывает эволюцию плотности бесстолкновительного газа в прямоугольном ящике с зеркальными стенками (при некоторых упрощающих предположениях). В отличие от классического необратимого уравнения теплопроводности

$$
u_{t}^{\prime}=\sigma^{2} \Delta u
$$

уравнение В.В. обратимо: оно выдерживает обращение времени, поэтому газ стремится равномерно заполнить ящик как при $t \rightarrow+\infty$, так и при $t \rightarrow-\infty$.

Изложение теории В. В. можно найти в двух его монографиях:

- «Тепловое равновесие по Гиббсу и Пуанкаре» (2002 г.),

- «Ансамбли Гиббса и неравновесная статистическая механика» (2008г.).

В нашем кратком очерке мы ничего не сказали о работах В. В. по интегрируемым системам, по различным аспектам релятивистской и квантовой механики, по динамике в пространствах постоянной кривизны, по спектральной теории.

НЕЛИНЕЙНАЯ ДИНАМИКА, 2010, Т. 6, № 3, с. 461-473 


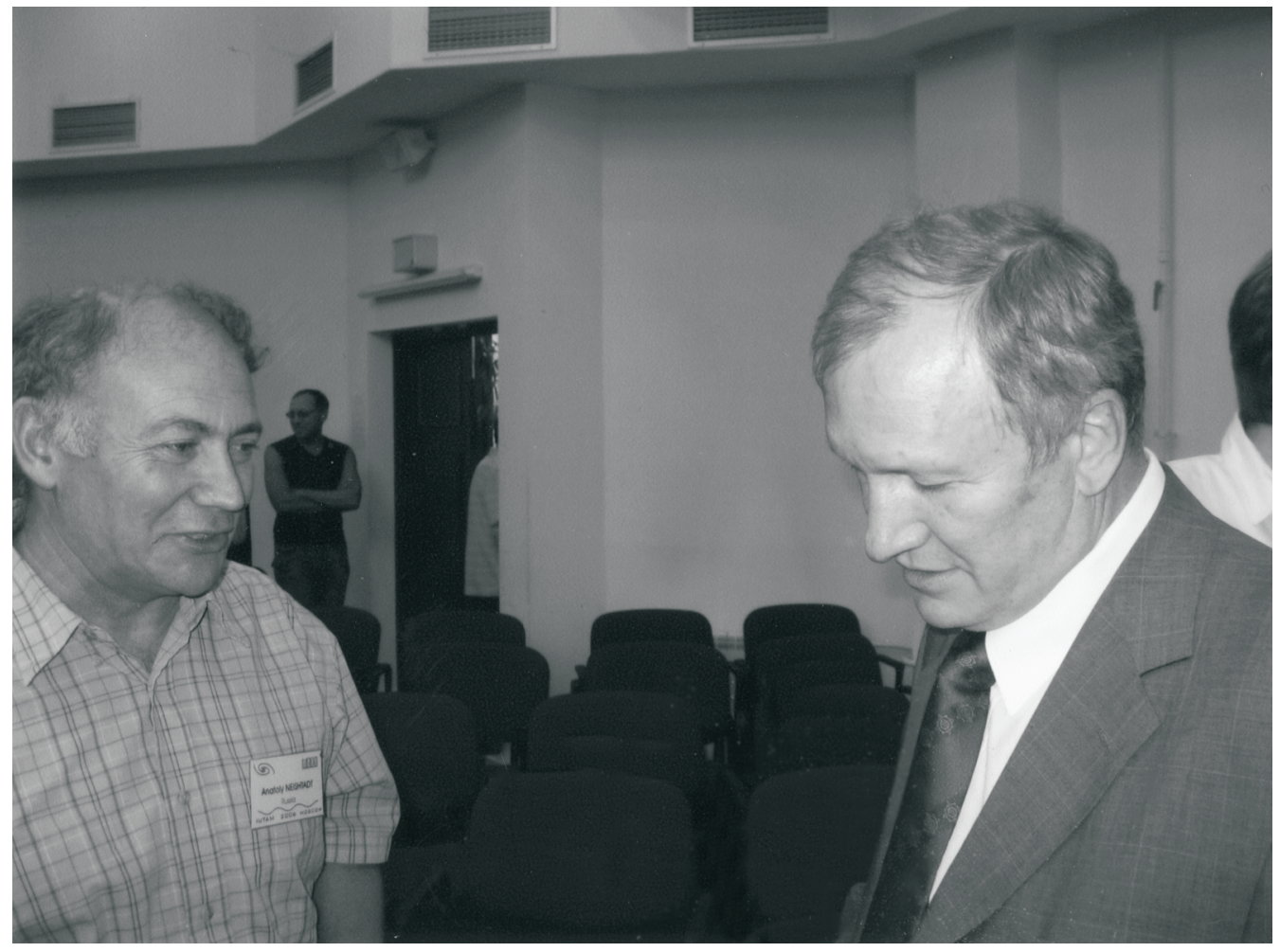

С А. И. Нейштадтом, IUTAM Symposium (2006)

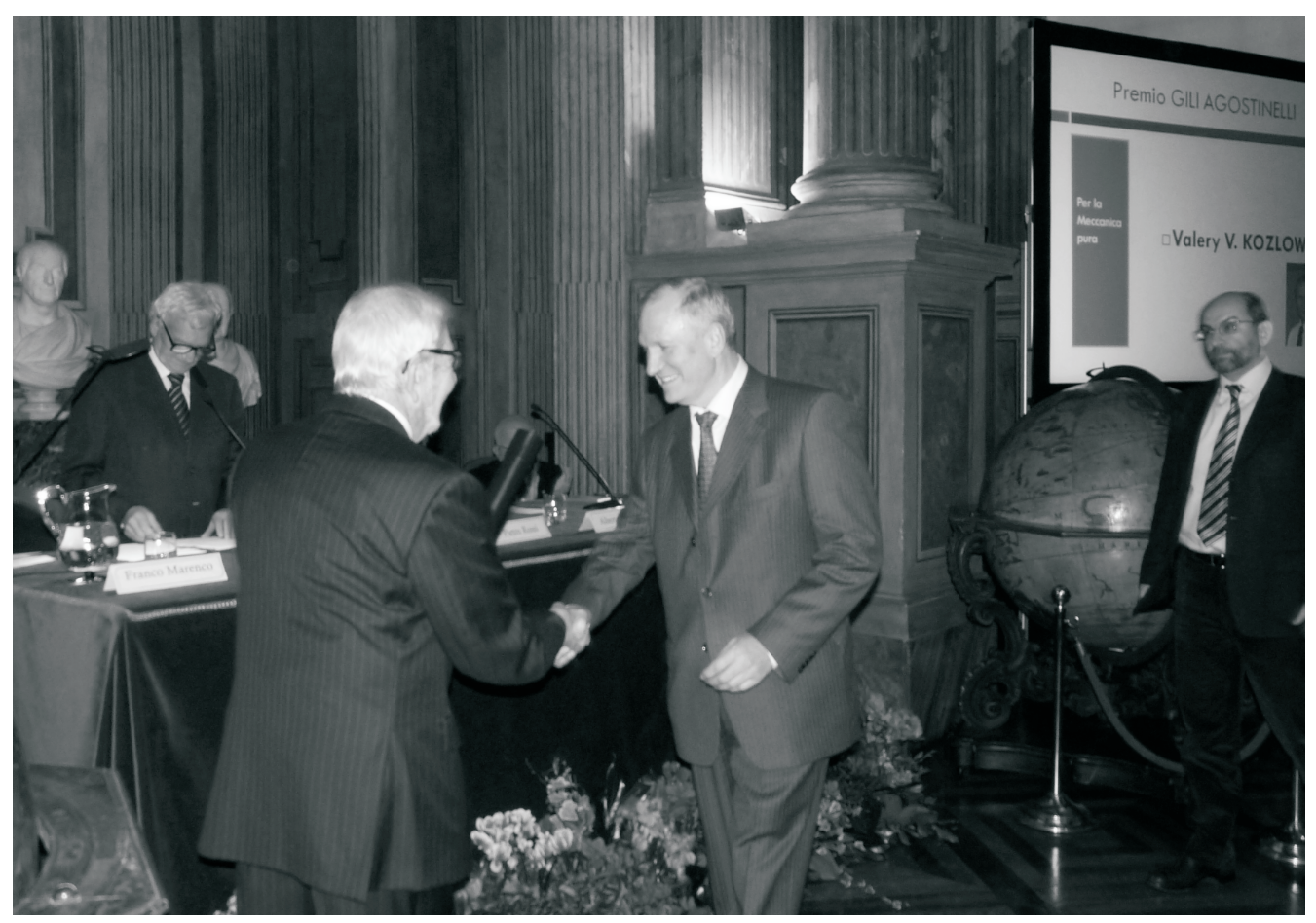

Вручение международной премии Gilli-Agostinelli Туринской академии наук (2009) 
У В. В. много научных наград. Кроме перечисленных выше, В. В. удостоен Государственной премии РФ (1994 г.), золотой медали им. Л. Эйлера РАН (2007 г.), международной премии Gilli-Agostinelli Туринской академии наук (2009г.) за лучшие работы последнего десятилетия по теоретической механике и классической математической физике.

В решении о присуждении В. В. премии Gilli-Agostinelli сказано: «Валерий Васильевич Козлов принадлежит к числу наиболее авторитетных специалистов по теоретической механике мирового уровня; его вклад в эту дисциплину оказал заметное влияние на ее развитие в последнее время. Его интересы сосредоточены в самых разных областях, причем в каждой из них ему удается получить значительные и разнообразные результаты, довольно часто окончательные. Его интересы простираются от динамики твердых тел до интегрируемости динамических уравнений и теории устойчивости, от вариационных методов и различных областей аналитической механики до теории удара и теории интегральных инвариантов, статистической механики и различных областей математической физики».

В 1997 году В. В. избран членом-корреспондентом Российской академии наук, а в 2000 году - академиком.

Для нас всех есть одна неразрешимая задача: как В.В. удается продолжать активно работать в науке, несмотря на очень большие административные нагрузки? Он работал заместителем декана механико-математического факультета по науке, проректором МГУ, заместителем министра образования, с 2001 года работает вице-президентом Российской академии наук, а сейчас еще и директором Математического института им. В. А. Стеклова. И за все эти годы интенсивность и глубина исследований В. В. не ослабевала!

В этот том вошла треть работ В. В. по математике, механике и математической физике. А еще есть восемь монографий, и четыре из них переведены на английский язык.

Мы адресуем эту книгу прежде всего молодежи. По работам В. В. можно многому научиться и выйти на передний край исследований по теории динамических систем и в смежных областях.

Сборник завершается двумя статьями В. В., в которых содержатся постановки новых, пока нерешенных задач. Интересно отметить, что темы своих первых исследований В.В. придумал сам. Это касается идеи и его первой опубликованной статьи, которая возникла в связи с чтением одной из работ С. А. Чаплыгина.

В.В. любит цитировать А. Пуанкаре: «Нет задач решенных и не решенных. А есть задачи, более решенные и менее решенные». Вот на этой оптимистической ноте мы и закончим наш очерк и предоставим возможность читателю познакомиться с оригинальными работами самого Валерия Васильевича.

\author{
А. В. Борисов, С.В. Болотин, А.А. Килин, \\ И. С. Мамаев, Д. В. Трещев \\ Январь, 2010
}

НЕЛИНЕЙНАЯ ДИНАМИКА, 2010, Т. 6, № 3, с. 461-473 


\section{Curriculum vitae \\ и список публикаций В.В. Козлова}

Валерий Васильевич Козлов родился 1 января 1950 года (Рязанская обл., СССР).

В 1972 г. закончил механико-математический факультет Московского государственного университета им. М. В. Ломоносова. Дипломная работа «Неинтегрируемость уравнений вращения тяжелого несимметричного твердого тела вокруг неподвижной точки».

1972-1973: Аспирант механико-математического факультета МГУ им. М. В. Ломоносова.

1974: Диссертация на соискание ученой степени кандидата физико-математических наук «Качественное исследование движения твердого тела в интегрируемых случаях» (защищена на механико-математическом факультете МГУ им. М. В. Ломоносова).

1978: Диссертация на соискание ученой степени доктора физико-математических наук «Вопросы качественного анализа в динамике твердого тела» (защищена на механикоматематическом факультете МГУ им. М. В. Ломоносова).

Научные интересы:

теоретическая и статистическая механика, смежные вопросы качественной теории дифференциальных уравнений, дифференциальной геометрии и топологии, вариационного исчисления.

Основные направления научных исследований:

общие принципы динамики, проблема интегрируемости уравнений движения, вариационные методы механики, теория устойчивости движения, динамика твердого тела, неголономная механика, теория удара, симметрии и интегральные инварианты, математические вопросы статистической механики, эргодическая теория и математическая физика.

\section{Должности:}

1974-1983: ассистент, доцент, старший научный сотрудник механико-математического факультета МГУ им. М. В. Ломоносова;

с 1983: профессор кафедры теоретической механики механико-математического факультета МГУ им. М. В. Ломоносова;

1980-1987: заместитель декана механико-математического факультета МГУ по научной работе;

1989-1998: проректор Московского государственного университета им. М. В. Ломоносова;

1997-2001: заместитель министра образования РФ - Главный ученый секретарь ВАК России;

1999-2005: заведующий кафедрой математической статистики и случайных процессов МГУ им. М. В. Ломоносова;

с 2001: вице-президент Российской академии наук; 
с 2003: заведующий отделом математических методов механики и статистической физики

Математического института им. В. А. Стеклова РАН;

с 2004: директор Математического института им. В. А. Стеклова РАН;

с 2005: заведующий кафедрой дифференциальных уравнений МГУ.

Член Совета по науке, образованию и технологиям при Президенте РФ. Организатор и главный редактор международного математического журнала «Regular and Chaotic Dynamics», главный редактор журнала «Известия РАН. Серия Математическая», заместитель главного редактора журнала «Вестник Московского университета», член редколлегий журналов «Доклады Академии наук», «Математические заметки» и «Russian Journal of Mathematical Physics».

\section{Членство в академиях и обществах:}

1995: член Национального комитета России по теоретической и прикладной механике;

1995: действительный член Российской академии естественных наук;

1997: член-корреспондент Российской академии наук;

2000: действительный член (академик) Российской академии наук;

2003: иностранный член Научного общества Сербии;

2006: член Национального комитета России по математике.

\section{Научные премии и медали:}

1973: Премия Ленинского комсомола;

1986: Ломоносовская премия I степени;

1988: Премия им. С. А. Чаплыгина Академии наук СССР;

1994: Государственная премия Российской Федерации в области науки и техники;

2000: Премия им. С. В. Ковалевской Российской академии наук;

2004: Золотая медаль Анри Пуанкаре Международной федерации нелинейных аналитиков (IFNA);

2007: Золотая медаль им. Леонарда Эйлера Российской академии наук;

2009: Премия им. К. Агостинелли Туринской академии наук.

\section{Государственные награды:}

1999: Орден Почета;

2005: Орден «За заслуги перед Отечеством» IV степени;

2009: Орден «За заслуги перед Отечеством» III степени. 


\section{НАУЧНЫЕ ПУБЛИКАЦИИ В.В.КОЗЛОВА}

1973 1. О некоторых свойствах частных интегралов канонических уравнений // Вестн. Моск. ун-та. Сер. 1. Математика. Механика. 1973. № 1. С. 81-84.

1974 2. О несуществовании аналитических интегралов канонических систем, близких к интегрируемым // Вестн. Моск. ун-та. Сер. 1. Математика. Механика. 1974. № 2. С. $77-82$.

3*1 Геометрия переменных действие-угол в задаче Эйлера-Пуансо // Вестн. Моск. ун-та. Сер. 1. Математика. Механика. 1974. № 5. С. 74-79.

1975 4. Динамические системы, возникающие на инвариантных торах задачи Ковалевской // ПММ. 1975. Т. 39. Вып. 1. С. 24-29.

5* Несуществование дополнительного аналитического интеграла в задаче о движении несимметрического тяжелого твердого тела вокруг неподвижной точки // Вестн. Моск. ун-та. Сер. 1. Математика. Механика. 1975. № 1. С. 105-110.

6* Новые периодические решения в задаче о движении тяжелого твердого тела вокруг неподвижной точки // ПММ. 1975. Т. 39. Вып. 3. С. 407-414.

1976 7. Несуществование аналитических интегралов вблизи положений равновесия гамильтоновых систем // Вестн. Моск. ун-та. Сер. 1. Математика. Механика. 1976. № 1. С. 110-115.

8* Об одной задаче Пуанкаре // ПММ. 1976. Т. 40. Вып. 2. С. 352-355.

9* Принцип наименьшего действия и периодические решения в задачах классической механики // ПММ. 1976. Т. 40. Вып. 3. С. 399-407.

10* Расщепление сепаратрис возмущенной задачи Эйлера-Пуансо // Вестн. Моск. ун-та. Сер. 1. Математика. Механика. 1976. №6. С. 99-104.

1977 11. О качественном анализе движения твердого тела в случае Горячева-Чаплыгина // ПММ. 1977. Т. 41. Вып. 2. С. 225-233.

12* О геометрии областей возможных движений с краем // Вестн. Моск. ун-та. Сер. 1. Математика. Механика. 1977. № 5. С. 118-120.

13. О структуре дополнительных интегралов в задаче о вращении твердого тела вокруг неподвижной точки // Исследования по механике жидких и твердых тел: Сб. ст. М.: Изд-во Моск. ун-та, 1977. С. 113-120.

14. Новые периодические решения задачи о движении тяжелого несимметричного твердого тела вокруг неподвижной точки // Исследования по механике жидких и твердых тел: Сб. ст. М.: Изд-во Моск. ун-та, 1977. С. 121-125.

1978 15* Об интегралах квазипериодических функций // Вестн. Моск. ун-та. Сер. 1. Математика. Механика. 1978. № 1. С. 106-115.

16. О теоремах динамики // ПММ. 1978. Т. 42. Вып. 1. С. 28-33 (совм. с Н. Н. Колесниковым).

\footnotetext{
${ }^{1}$ Здесь и далее звездочкой отмечены публикации, которые вошли в том «Избранные работы по математике, механике и математической физике» (в настоящем списке - 225).
} 
17* Либрация в системах со многими степенями свободы // ПММ. 1978. Т. 42. Вып. 2. С. 245-250 (совм. с С. В. Болотиным).

18* Несуществование однозначных интегралов и ветвление решений в динамике твердого тела // ПММ. 1978. Т. 42. Вып. 3. С. 400-406.

1979 19* Топологические препятствия к интегрируемости натуральных механических систем // Докл. АН СССР. 1979. Т. 249. №6. С. 1299-1302.

20* Об интегрируемости гамильтоновых систем // Вестн. Моск. ун-та. Сер. 1. Математика. Механика. 1979. №6. С. 88-91.

1980 21. Периодические колебания составного маятника // ПММ. 1980. Т. 44. Вып. 2. C. $238-244$.

22* Об асимптотических решениях уравнений динамики // Вестн. Моск. ун-та. Сер. 1. Математика. Механика. 1980. № 4. С. 84-89 (совм. с С. В. Болотиным).

23. О колебаниях одномерных систем с периодическим потенциалом // Вестн. Моск. ун-та. Сер. 1. Математика. Механика. 1980. №6. С. 104-107.

24. Методы качественного анализа в динамике твердого тела. М.: Изд-во Моск. ун-та, 1980. 231 с. (2-е издание, дополненное: М.-Ижевск: НИЦ «Регулярная и хаотическая динамика», 2000. 248 с.)

1981 25. Неустойчивость равновесия в потенциальном поле // УМН. 1981. Т. 36. Вып. 1. C. 209-210.

26. О неустойчивости равновесия в потенциальном поле // УМН. 1981. Т. 36. Вып. 3. C. 215-216.

27. Неустойчивость равновесия в потенциальном поле с учетом сил вязкого трения // ПММ. 1981. Т. 45. Вып. 3. С. 570-572.

28* Две интегрируемые задачи классической динамики // Вестн. Моск. ун-та. Сер. 1. Математика. Механика. 1981. № 4. С. 80-83.

1982 29* Об асимптотических решениях уравнений классической механики // Докл. АН СССР. 1982. Т. 263. № 2. С. 285-289 (совм. с В. П. Паламодовым).

30. Динамика систем с неинтегрируемыми связями: I // Вестн. Моск. ун-та. Сер. 1. Математика. Механика. 1982. № 3. С. 92-100.

31. Динамика систем с неинтегрируемыми связями: II // Вестн. Моск. ун-та. Сер. 1. Математика. Механика. 1982. № 4. С. 70-76.

32. Усреднение в окрестности устойчивых периодических движений // Докл. AH CCCP. 1982. T. 264. № 3. C. 567-570.

33* Асимптотические решения уравнений классической динамики // ПММ. 1982. Т. 46. Вып. 4. С. 573-577.

34* Неинтегрируемость уравнений Кирхгофа // Докл. АН СССР. 1982. Т. 266. № 6. С. 1298-1300 (совм. с Д. А. Онищенко).

35. Уравнения Гамильтона задачи о движении твердого тела с неподвижной точкой в избыточных координатах // Teorijska i primenjena Mehanika. 1982. Vol. 8. P. 59-65. 
36. Гипотеза о существовании асимптотических движений в классической механике // Функц. анализ и его приложения. 1982. Т. 16. Вып. 4. С. 72-73.

1983 37. Интегрируемость и неинтегрируемость в гамильтоновой механике // УМН. 1983. т. 38. Вып. 1. С. 3-67.

38. Замечания о стационарных вихревых движениях сплошной среды // ПММ. 1983. Т. 47. Вып. 2. С. 341-342.

39. Динамика систем с неинтегрируемыми связями: III // Вестн. Моск. ун-та. Сер. 1. Математика. Механика. 1983. № 3. С. 102-111.

40* Реализация неинтегрируемых связей в классической механике // Докл. АН СССР. 1983. Т. 272. № 3. С. 550-554.

41* Гидродинамика гамильтоновых систем // Вестн. Моск. ун-та. Сер. 1. Математика. Механика. 1983. №6. С. 10-22.

1985 42. Вариационное исчисление в целом и классическая механика // УМН. 1985. Т. 40. Вып. 2. С. 33-60.

43. Интегрируемые случаи задачи о движении точки по трехмерной сфере в силовом поле с потенциалом четвертой степени // Вестн. Моск. ун-та. Сер. 1. Математика. Механика. 1985. № 3. С. 93-95.

$44 * \mathrm{~K}$ теории интегрирования уравнений неголономной механики // Успехи механики. 1985. Т. 8. Вып. 3. С. 85-107.

45. Математические аспекты классической и небесной механики // Современные проблемы математики. Фундаментальные направления. Т. 3. М.: ВИНИТИ, 1985. 304 с. (совм. с В.И. Арнольдом и А. И. Нейштадтом).

46* K задаче о вращении твердого тела в магнитном поле // Изв. АН СССР. МТT. 1985. №6. С. 28-33.

47. Неинтегрируемость общей задачи о вращении динамически симметричного твердого тела с неподвижной точкой: I // Вестн. Моск. ун-та. Сер. 1. Математика. Механика. 1985. №6. С. 73-81 (совм. с Д. В. Трещевым).

1986 48. Неинтегрируемость общей задачи о вращении динамически симметричного твердого тела с неподвижной точкой: II // Вестн. Моск. ун-та. Сер. 1. Математика. Механика. 1986. № 1. С. 39-41 (совм. с Д. В. Трещевым).

49. Некоторые аспекты теории динамических систем // Геометрия, дифференциальные уравнения и механика: Сб. ст. М.: Изд-во Моск. ун-та, 1986. С. 4-18.

50. Об устойчивости равновесий неголономных систем // Докл. АН СССР. 1986. T. 288. № 2. С. 289-291.

51. Расщепление сепаратрис и рождение изолированных периодических решений в гамильтоновых системах с полутора степенями свободы // УМН. 1986. Т. 41. Вып. 5. С. 177-178.

52* Релятивистский вариант гамильтонова формализма и волновые функции водородоподобного атома // Вестн. Моск. ун-та. Сер. 1. Математика. Механика. 1986. № 5. С. 11-20 (совм. с Е. М. Никишиным).

53* Асимптотические движения и проблема обращения теоремы Лагранжа-Дирихле // ПММ. 1986. Т. 50. Вып. 6. С. 928-937. 
1987 54. Phenomena of Nonintegrability in Hamiltonian Systems // Proc. Intern. Congr. Math. Berkeley. USA. 1987. P. 1161-1170.

55. О существовании интегрального инварианта гладких динамических систем // ПММ. 1987. Т. 51. Вып. 4. С. 538-545.

56. Динамика систем с неинтегрируемыми связями IV. Интегральные принципы // Вестн. Моск. ун-та. Сер. 1. Математика. Механика. 1987. № 5. С. 76-83.

1988 57* Об инвариантных мерах уравнений Эйлера-Пуанкаре на алгебрах Ли // Функц. анализ и его приложения. 1988. Т. 22. Вып. 1. С. 69-70.

58. Об интегрируемости гамильтоновых систем с торическим пространством положений // Матем. сб. 1988. Т. 135. №1. С. 119-138 (совм. с Д. В. Трещевым).

59. Ветвление решений и полиномиальные интегралы в обратимой системе на торе // Матем. заметки. 1988. Т. 44. № 1. С. 100-104.

60. K теории возмущений гамильтоновых систем с некомпактными инвариантными поверхностями // Вестн. Моск. ун-та. Сер. 1. Математика. Механика. 1988. № 2. C. $55-61$.

61* О полиномиальных интегралах системы взаимодействующих частиц // Докл. AH CCCP. 1988. T. 301. № 4. C. 785-788.

62. О группах симметрий динамических систем // ПММ. 1988. Т.52. Вып. 4. C. 531-541.

63. Динамика систем с неинтегрируемыми связями. V. Принцип освобождаемости и условие идеальности связей // Вестн. Моск. ун-та. Сер. 1. Математика. Механика. 1988. №6. C. 51-54.

64* Конструктивный метод обоснования теории систем с неудерживающими связями // ПММ. 1988. Т. 52. Вып. 6. С. 883-894.

65. Геометрическое представление Пуансо в динамике многомерного твердого тела // Труды семинара по векторному и тензорному анализу. 1988. Вып. 23. С. 30-36 (совм. с Д. В. Зенковым).

1989 66. Integrable and Nonintegrable Hamiltonian Systems // Sov. Sci. Rev.; Sect. C. Math. Phys. Rev. 1989. Vol. 8. P. 1-81.

67* Об одной задаче Кельвина // ПММ. 1989. Т. 53. Вып. 1. С. 165-167.

68* Полиномиальные интегралы гамильтоновых систем с экспоненциальным взаимодействием // Изв. АН СССР. Сер. Математическая. 1989. Т. 53. С. 537-556 (совм. с Д. В. Трещевым).

69. О полиномиальных интегралах динамических систем с полутора степенями свободы // Матем. заметки. 1989. Т. 45. № 4. С. 46-52.

70* О падении тяжелого твердого тела в идеальной жидкости // Изв. АН СССР. MTT. 1989. № 5. C. 10-17.

71* Принципы динамики и сервосвязи // Вестн. Моск. ун-та. Сер. 1. Математика. Механика. 1989. № 5. С. 59-66.

72. Числа Ковалевской обобщенных цепочек Тоды // Матем. заметки. 1989. Т. 45. № 5. С. 17-28 (совм. с Д. В. Трещевым). 
73* Об ударе с трением // Изв. АН СССР. МТТ. 1989. № 6. С. 54-60.

74. Об устойчивости равновесия в непотенциальном силовом поле // Teorijska i primenjena Mehanika. 1989. Vol. 15. Р. 139-145 (совм. с В. А. Вуйичичем).

1990 75* K задаче о падении тяжелого твердого тела в сопротивляющейся среде // Вестн. Моск. ун-та. Сер. 1. Математика. Механика. 1990. №1. С. 79-86.

76. Конструктивный подход к обоснованию динамики систем со связями (к 200-летию «Аналитической механики» Ж.-Л. Лагранжа) // Теоретическая механика: Сб. науч.-метод. ст.: Вып. 20. М.: Изд-во МПИ. 1990. С. 8-15.

77* Вихревая теория волчка // Вестн. Моск. ун-та. Сер. 1. Математика. Механика. 1990. № 4. С. 56-62.

78* О реализации голономных связей // ПММ. 1990. Т. 54. Вып. 5. С. 858-861 (совм. с А. И. Нейштадтом).

79* О группах симметрий геодезических потоков на замкнутых поверхностях // Матем. заметки. 1990. Т. 48. Вып. 5. С. 62-67.

1991 80* О стохастизации плоско-параллельных течений идеальной жидкости // Вестн. Моск. ун-та. Сер. 1. Математика. Механика. 1991. № 1. С. 72-75.

81. Биллиарды: Генетическое введение в динамику систем с ударами. М.: Изд-во Моск. ун-та, 1991. 168 с. (совм. с Д. В. Трещевым).

82. Об устойчивости положений равновесия в нестационарном силовом поле // ПММ. 1991. Т. 55. Вып. 1. С. 12-19.

83. K задаче Ляпунова об устойчивости по отношению к заданным функциям состояния // ПММ. 1991. Т. 55. Вып. 4. С. 555-559 (совм. с В. А. Вуйичичем).

84. Об устойчивости периодических траекторий пространственного биллиарда // ПММ. 1991. Т. 55. Вып. 5. С. 713-717 (совм. с И. И. Чигуром).

85. Устойчивость периодических траекторий и многочлены Чебышева // Вестн. Моск. ун-та. Сер. 1. Математика. Механика. 1991. № 5. С. 7-13.

1992 86* Тензорные инварианты квазиоднородных систем дифференциальных уравнений и асимптотический метод Ковалевской - Ляпунова // Матем. заметки. 1992. Т. 51. Вып. 2. С. 46-52.

87* Kepler's Problem in Constant Curvature Spaces / Celestial Mech. Dynam. Astronom. 1992. V.54. Р. 393-399 (совм. с А. О. Хариным).

88. K вопросу о реализации связей в динамике // ПММ. 1992. Т.56. Вып. 4. C. 692-698.

89* Линейные системы с квадратичным интегралом // ПММ. 1992. Т.56. Вып. 6. C. 900-906.

90. Об импульсном изоэнергетическом управлении // Вестн. Моск. ун-та. Сер. 1. Математика. Механика. 1992. № 5. С. 69-71 (совм. с А. Ю. Хмелевской).

1993 91* Dynamical Systems Determined by the Navier-Stockes Equations // Russ. J. Math. Phys. 1993. Vol. 1. No. 1. P. 57-69. 
92. Об инвариантных мерах уравнений Эйлера-Пуанкаре на унимодулярных группах // Вестн. Моск. ун-та. Сер. 1. Математика. Механика. 1993. № 2. С.91-95 (совм. с В. А. Ярощук).

93. Лиувиллевость инвариантных мер вполне интегрируемых систем и уравнение Монжа-Ампера // Матем. заметки. 1993. Т. 53. Вып. 4. С. 45-52.

94. О падении тяжелого цилиндрического твердого тела в жидкости // Изв. РАН. MTT. 1993. № 4. С. 113-117.

95* О степени неустойчивости // ПММ. 1993. Т. 57. Вып. 5. С. 14-19.

96*. Симметрия и топология динамических систем с двумя степенями свободы // Матем. сб. 1993. Т. 184. № 9. С. 125-148 (совм. с Н. В. Денисовой).

1994 97*. О динамике в пространствах постоянной кривизны // Вестн. Моск. ун-та. Сер. 1. Математика. Механика. 1994. № 2. С. 28-35.

98. Интегрируемые системы на сфере с потенциалами упругого взаимодействия // Матем. заметки. 1994. Т. 56. Вып. 3. С. 74-79 (совм. с Ю. Н. Федоровым).

99. Symmetries and Topology of Dynamical Systems with Two Degrees of Freedom // Hamiltonian Mechanics: Integrability and Chaotic Behaviour. NATO ASI Series. Series B: Physics Vol. 331. New York: Plenum Press, 1991. P. 167-172.

100. О равновесиях неголономных систем // Вестн. Моск. ун-та. Сер. 1. Математика. Механика. 1994. №3. С. 74-79.

101* Об асимптотических движениях систем с диссипацией // ПММ. 1994. Т.58. Вып. 5. С. 31-36.

102* Полиномиальные интегралы геодезических потоков на двумерном торе // Maтем. сб. 1994. Т. 185. № 12. С. 49-64 (совм. с Н. В. Денисовой).

103. О тензорных инвариантах динамических систем на трехмерных многообразиях // Teorijska i Primenjena Mehanika. 1994. Vol. 20. P. 119-129.

1995 104* Некоторые интегрируемые обобщения задачи Якоби о геодезических на эллипсоиде // ПММ. 1995. Т. 59. Вып. 1. С. 3-9.

105. Симметрии, топология и резонансы в гамильтоновой механике. Ижевск: Изд-во Удмуртск. гос. ун-та, 1995. 429 с.

106. Принцип Мопертюи и геодезические потоки на сфере, возникающие из интегрируемых случаев динамики твердого тела // УМН. 1995. Т. 50. Вып. 3. С. 3-32 (совм. с А. В. Болсиновым и А. Т. Фоменко).

107* Об интегральных инвариантах уравнений Гамильтона // Матем. заметки. 1995. Т. 58. Вып. 3. С. 379-393.

108* Symmetry Fields of Geodesic Flows // Russ. J. Math. Phys. 1995. Vol. 3. No. 3. P. 279-295 (совм. с С. В. Болотиным).

109* К теории систем с односторонними связями // ПММ. 1995. Т.59. Вып. 4. С. 531-539 (совм. с М. В. Дерябиным).

110. К теории реономных систем // Вестн. Моск. ун-та. Сер. 1. Математика. Механика. 1995. № 5. С. 79-85 (совм. с В. А. Вуйичичем).

111. О решениях систем дифференциальных уравнений с обобщенной асимптотикой // Матем. заметки. 1995. Т. 58. Вып. 6. С. 851-861 (совм. с С. Д. Фуртой).

НЕЛИНЕЙНАЯ ДИНАМИКА, 2010, Т. 6, № 3, с. 474-488 
112. О многозначных интегралах уравнений Гамильтона // Проблемы нелинейного анализа в инженерных системах. 1995. Вып. 1. С. 30-34.

113* Various Aspects of $n$-Dimentional Rigid Body Dynamics // Amer. Math. Soc. Transl. Ser. 2. 1995. Vol. 168. P. 141-171 (совм. с Ю. Н. Федоровым).

114. Hydrodynamics of Noncommutative Integration of Hamiltonian Systems // Advances in Math. Sciences. Dynamical Systems in Classical Mechanics. Amer. Math. Soc. Transl. Ser. 2. 1995. Vol. 168. P. 227-238.

115* Problemata Nova, ad Quorum Solutionem Mathematici Invitantur // Advances in Math. Sciences. Dynamical Systems in Classical Mechanics. Amer. Math. Soc. Translations. Ser. 2. 1995. Vol. 168. P. 239-254.

1996 116. Symmetries and Regular Behavior of Hamiltonian Systems // Chaos. 1996. Vol.6. No. 1. P. 1-5.

117. Аналитические свойства решений уравнений Эйлера-Пуанкаре на разрешимых алгебрах Ли // Вестн. Моск. ун-та. Сер. 1. Математика. Механика. 1996. № 3. С. 60-65 (совм. с О. В. Измайловой).

118. Топология областей возможности движения интегрируемых систем // Матем. сб. 1996. Т. 187. № 5. С. 60-64 (совм. с В. В. Теном).

119* О движении диска по наклонной плоскости // Изв. РАН. МТТ. 1996. № 5. С. $29-35$.

120* Об одном обобщении метода Гамильтона-Якоби // ПММ. 1996. Т. 60. Вып. 6. С. 929-939.

121. Асимптотики решений сильно нелинейных систем дифференциальных уравнений. М.: Изд-во Моск. ун-та, 1996. 244 с. (совм. с С. Д. Фуртой).

1997 122. Замкнутые орбиты и хаотическая динамика заряда в периодическом электрическом поле // Регулярная и хаотическая динамика. 1997. Т. 2. № 1. С. 3-12.

123. Задача о падении диска, движущегося по горизонтальной плоскости // Изв. РАН. MTT. 1997. № 1. С. 7-13 (совм. с А. А. Афониным).

124* О стабилизации неустойчивых равновесий зарядов сильными магнитными полями // ПММ. 1997. Т. 61. Вып. 3. С. 390-397.

125. Усреднение в окрестности устойчивых инвариантных торов // Регулярная и хаотическая динамика. 1997. Т. 2. №3/4. С. 41-46.

126. О диффузии в гамильтоновых системах // Вестн. Моск. ун-та. Сер. 1. Математика. Механика. 1997. № 5. С. 49-52 (совм. с Н. Г. Мощевитиным).

1998 127* Ветвление решений и полиномиальные интегралы уравнений динамики // ПММ. 1998. Т. 62. Вып. 1. С. 3-11.

128. Об устойчивости равноускоренных движений // ПММ. 1998. Т.62. Вып. 5. C. $726-731$.

129. Интегральные инварианты после Пуанкаре и Картана // Интегральные инварианты / Э. Картан. М.: УРСС, 1998. С. 215-260.

130* Гидродинамическая теория одного класса конечномерных диссипативных систем // Тр. МИАН. 1998. Т. 223. С. 181-186.

131. Общая теория вихрей. Ижевск: УдГУ, 1998. 238 с. 
132. О периодических решениях уравнений Дуффинга // Тр. науч. семин. Ин-та машиноведения им. А. А. Благонравова. 1998. С. 75-88.

1999 133* Условие вмороженности поля направлений, малые знаменатели и хаотизация стационарных течений вязкой жидкости // ПММ. 1999. Т. 63. Вып. 2. С. 237-244.

134. Неинтегрируемость системы взаимодействующих частиц с потенциалом Дайсона // Докл. РАН. 1999. Т. 366. № 1. С. 30-31 (совм. с А. В. Борисовым).

135* Canonical Gibbs Distribution and Thermodynamics of Mechanical Systems with a Finite Number of Degrees of Freedom // Regul. Chaotic Dyn. 1999. Vol.4. No. 2. P. 44-54.

136. О хаотизации колебаний связанных маятников // Докл. РАН. 1999. Т. 367. № 2. С. 191-193 (совм. с Н. В. Денисовой).

137. О неустойчивости изолированных равновесий динамических систем с инвариантной мерой в нечетномерном пространстве // Матем. заметки. 1999. Т. 65. Вып. 5. С. 674-680 (совм. с Д. В. Трещевым).

138. Hamiltonian Systems with Three Degrees of Freedom and Hydrodynamics // Hamiltonian Systems with Three or More Degrees of Freedom (S'Agaro, Spain, June 19-30, 1995). (NATO ASI Series. Series C: Math. and Phys. Sciences. Vol.533.) Dordrecht: Kluwer, 1999. P. 127-133.

139. Принцип относительности и силы инерции // Теоретическая механика: Сб. науч.-метод. ст.: Вып. 21. М.: Изд-во МПИ. 1999. С. 16-23 (совм. с А. О. Хариным).

2000 140. Полиномиальные интегралы обратимых механических систем с конфигурационным пространством в виде двумерного тора // Матем. сб. 2000. Т. 191. № 2. С. 43-63 (совм. с Н. В. Денисовой).

141. Billiards, Invariant Measures, and Equilibrium Thermodynamics // Regul. Chaotic Dyn. 2000. Vol. 5. No. 2. P. 129-138.

142. Термодинамика гамильтоновых систем и распределение Гиббса // Докл. РАН. 2000. T. 370. № 3. С. 325-327.

143. Вихревая теория адиабатических равновесных процессов // Вестн. Моск. ун-та. Сер. 1. Математика. Механика. 2000. № 2. С. 35-40.

144. Статистическая динамика системы связанных маятников // Докл. РАН. 2000. Т. 373. № 5. С. 597-599.

145. Integrable Analogue of the Gauss Principle // Facta Universitatis. 2000. Vol. 2. No. 10. P. 1055-1060.

146* Теоремы Ньютона и Айвори о притяжении в пространствах постоянной кривизны // Вестн. Моск. ун-та. Сер. 1. Математика. Механика. 2000. № 5. С. 43-47.

147* Двузвенные биллиардные траектории: экстремальные свойства и устойчивость // ПММ. 2000. Т. 64. Вып. 6. С. 942-946.

2001 148. Первый метод Ляпунова для сильно нелинейных систем дифференциальных уравнений // Нелинейная механика / В. М. Матросов и др. (ред.). М.: Физматлит, 2001. $432 \mathrm{c}$.

149* Kinetics of Collisionless Continuous Medium // Regul. Chaotic Dyn. 2001. Vol.6. No. 3. P. 235-251.

НЕЛИНЕЙНАЯ ДИНАМИКА, 2010, Т. 6, № 3, с. 474-488 
150. Неэкспоненциальная атмосфера и неканонические распределения вероятностей // Докл. РАН. 2001. Т. 380. № 3. С. 346-348.

151. О движении изменяемого тела в идеальной жидкости // ПММ. 2001. Т. 65. Вып. 4. С. 529-601 (совм. с С. М. Рамодановым).

152. Диффузия в системах с интегральным инвариантом на торе // Докл. РАН. 2001. T. 381. № 5. С. 596-598.

153. Гироскопическая стабилизация и параметрический резонанс // ПММ. 2001. Т. 65. Вып. 5. С. 739-745.

154. О равномерном распределении // Изв. высших учебн. заведений. Северо-Кавказский регион. Естественные науки. 2001. С. 96-99.

2002 155. On Justification of Gibbs Distribution // Regul. Chaotic Dyn. 2002. Vol.7. No.1. P. 1-10.

156. Об эффекте «выныривания» тяжелого твердого тела в жидкости // Изв. РАН. МTT. 2002. № 1. С. 68-74 (совм. с М. В. Дерябиным).

157. О движении в идеальной жидкости тела с жесткой оболочкой и меняющейся геометрией масс // Докл. РАН. 2002. Т. 382. № 4. С. 478-481 (совм. с С. М. Рамодановым).

158* Тепловое равновесие по Гиббсу и Пуанкаре // Докл. РАН. 2002. Т. 382. № 5. C. 602-605.

159. Математические аспекты классической и небесной механики. 2-е изд. М.: УРСС, 2002. 414 с. (совм. с В. И. Арнольдом и А. И. Нейштадтом).

160. Стационарные движения сплошной среды, резонансы и лагранжева турбулентность // ПММ. 2002. Т. 66. Вып. 6. С. 939-947 (совм. с Н. В. Денисовой).

161. Суммирование расходящихся рядов и эргодические теоремы // Тр. семин. им. И. Г. Петровского. 2002. Вып. 22. С. 142-168.

162. Тепловое равновесие по Гиббсу и Пуанкаре. М.-Ижевск: Инст. компьютерн. иссл., 2002. 319 с.

2003 163. Числа вращения Пуанкаре и средние Рисса и Вороного // Матем. заметки. 2003. Т. 74. Вып. 2. С. 314-315 (совм. с Т. Мадсен).

164. Слабая сходимость решений уравнения Лиувилля для нелинейных гамильтоновых систем // ТМФ. 2003. Т. 134. № 3. С. 388-400 (совм. с Д. В. Трещевым).

165. О движении в идеальной жидкости тела, содержащего внутри себя подвижную сосредоточенную массу // ПММ. 2003. Т. 67. Вып. 4. С.620-633 (совм. с Д. А. Онищенко).

166. Условия рациональности отношения эллиптических интегралов и большая теорема Понселе // Вестн. Моск. ун-та. Сер. 1. Математика. Механика. 2003. № 4. C. 6-13.

167. Слабые пределы вероятностных распределений в системах с нестационарными возмущениями // Докл. РАН. 2003. Т. 389. № 5. С. 605-607.

168. Weak Convergence of Measures in Conservative Systems // Записки научных семинаров ПОМИ РАН. 2003. Т. 300. С. 194-205 (совм. с Д. В. Трещевым). 
169. Эволюция мер в фазовом пространстве нелинейных гамильтоновых систем // ТМФ. 2003. Т. 136. № 3. С. 496-506 (совм. с Д. В. Трещевым).

170* On New Forms of the Ergodic Theorem // J. Dyn. Control Syst. 2003. Vol. 9. No. 3. Р. 449-453 (совм. с Д. В. Трещевым).

171. Galton Board // Regul. Chaotic Dyn. 2003. Vol.8. No.4. P.431-439 (совм. с М. Ю. Митрофановой).

172* Спектр линейной гамильтоновой системы и симплектическая геометрия комплексного пространства Артина // Докл. РАН. 2003. Т. 393. № 4. С. 453-455.

2004 173. Notes on Diffusion in Collisionless Medium // Regul. Chaotic Dyn. 2004. Vol. 9. No. 1. P. 29-34.

174. Статистическое равновесие по Гиббсу и Пуанкаре в системах с медленно меняющимися параметрами // Докл. РАН. 2004. Т. 395. № 2. С. 169-173.

175. Линейные системы с квадратичным интегралом и симплектическая геометрия пространств Артина // ПММ. 2004. Т. 68. Вып. 3. С. 371-383.

176. Полиномиальные законы сохранения квантовых систем // ТМФ. 2004. Т. 140. № 3. С. 460-479 (совм. с Д. В. Трещевым).

177. Billiards, Invariant Measures, and Equilibrium Thermodynamics: II // Regul. Chaotic Dyn. 2004. Vol. 9. No. 2. P. 91-100.

178. О равномерном распределении на торе // Вестн. Моск. ун-та. Сер. 1. Матем. Механика. 2004. № 2. С. 22-29.

179. О весовых средних значениях слабозависимых случайных величин // Вестн. Моск. ун-та. Сер. 1. Матем. Механика. 2004. № 5. С. 34-37 (совм. с Т. Мадсен и А. А. Сорокиным).

180. Динамика изменяемых систем и группы Ли // ПММ. 2004. Т.68. Вып. 6. C. 899-905.

181. Законы сохранения в квантовых системах на торе // Докл. РАН. 2004. Т. 398. № 3. С. 314-318 (совм. с Д. В. Трещевым).

2005 182* О степени устойчивости // Дифференц. уравн. 2005. Т. 41. № 2. С. 186-192 (совм. c А. А. Карапетяном).

183* Весовые средние, строгая эргодичность и равномерное распределение // Матем. заметки. 2005. Т. 78. Вып. 3. С. 358-367.

184. Замечания об одной теореме Ли, касающейся точной интегрируемости дифференциальных уравнений // Дифференц. уравн. 2005. Т. 41. № 4. С. 553-555.

185. Равномерное распределение и сходимость по Вороному // Матем. сб. 2005. Т. 196. № 10. С. 103-110 (совм. с Т. Мадсен).

186. О периодических траекториях биллиарда в магнитном поле // ПММ. 2005. Т. 69. Вып. 6. С. 953-960 (совм. с С. А. Поликарповым).

187* Топологические препятствия к существованию квантовых законов сохранения // Докл. РАН. 2005. Т. 401. № 5. С. 603-606.

188. Замечания о собственных числах вещественных матриц // Докл. РАН. 2005. T. 403. № 5. C. 589-592. 
189. К задаче о поршне // Докл. РАН. 2005. Т. 403. №6. С. 752-755.

190* Ограничения квадратичных форм на лагранжевы плоскости, квадратные матричные уравнения и гироскопическая стабилизация // Функц. анализ и его приложения. 2005. Т. 39. Вып. 4. С. 32-47.

191. Весовые средние, равномерное распределение и строгая эргодичность // УМН. 2005. Т. 60. Вып. 6. С. 115-138.

2006 192. Функция Вигнера и диффузия в бесстолкновительной среде, состоящей из квантовых частиц // ТВП. 2006. Т. 51. Вып. 1. С. 109-125 (совм. с О. Г. Смоляновым).

193. О суммируемых с квадратом решениях уравнения Клейна-Гордона на многообразиях // Докл. РАН. 2006. Т. 408. № 3. С. 3-10 (совм. с И. В. Воловичем).

194* Finite Action Klein-Gordon Solutions on Lorentizian Manifolds // Int. J. Geom. Methods Mod. Phys. 2006. Vol. 3. No. 7. P. 1-9 (совм. с И. В. Воловичем).

195. О падении тяжелого твердого тела в идеальной жидкости // Тр. ин-та матем. и механ. 2006. Т. 12. №1. С. 25-47 (совм. с А. В. Борисовым и И. С. Мамаевым).

196. Информационная энтропия в задачах классической и квантовой статистической механики // Докл. РАН. 2006. Т. 411. № 5. С. 587-590 (совм. с О. Г. Смоляновым).

2007 197* Тонкая и грубая энтропия в задачах статистической механики // ТМФ. 2007. Т. 151. № 1. С. 120-137 (совм. с Д. В. Трещевым).

198. Инвариантные плоскости, индексы инерции и степени устойчивости линейных уравнений динамики // Тр. МИАН. 2007. Т. 258. С. 154-161.

199. Әйлер и математические методы механики (к 300-летию со дня рождения Леонарда Эйлера) // УМН. 2007. Т. 62. № 4. С. 3-26.

200. Асимптотическая устойчивость и родственные задачи динамики падающего тяжелого твердого тела // Нелинейная динамика. 2007. Т. 3. № 3. С. 255-296 (совм. с А. В. Борисовым и И. С. Мамаевым).

201* Статистические свойства биллиардов на многогранниках // Докл. РАН. 2007. T. 416. № 3. С. 302-305.

202. Asymptotic Stability and Associated Problems of Dynamics of Falling Rigid Body // Regul. Chaotic Dyn. 2007. Vol. 12. No.5. P.531-565 (совм. с A. В. Борисовым и И. С. Мамаевым).

203. Ансамбли Гиббса, равнораспределенность энергии симпатических осцилляторов и статистические модели термостата // Нелинейная динамика. 2007. Т. 3. № 2. C. 123-140.

204* Динамические системы на торе с многозначными интегралами // Динамические системы и оптимизация: K 70-летию со дня рождения академика Дмитрия Викторовича Аносова: Сб. ст. (Тр. МИАН Т. 256.) М.: Наука, 2007. С. 201-218.

205. Уравнение вихря 2D-гидродинамики, стационарное кинетическое уравнение Власова и развитая турбулентность // Нелинейная динамика. 2007. Т. 2. № 4. C. $425-434$.

206. Слабая сходимость состояний в квантовой статистической механике // Докл. РАН. 2007. Т. 417. № 2. С. 180-184 (совм. с О. Г. Смоляновым). 
2008 207. Тождество Лагранжа и его обобщения // Нелинейная динамика. 2008. Т. 4. № 2. C. $157-168$.

208. Gibbs Ensembles, Equidistribution of the Energy of Sympathetic Oscillators and Statistical Models of Thermostat // Regul. Chaotic Dyn. 2008. Vol.13. No.3. P. $141-154$.

209. Lagrange's Identity and Its Generalizations // Regul. Chaotic Dyn. 2008. Vol. 13. No. 2. P. 71-80.

210. Ансамбли Гиббса и неравновесная статистическая механика. М.-Ижевск: НИЦ «Регулярная и хаотическая динамика», 2008. 203 с.

211* Гироскопическая стабилизация вырожденных равновесий и топология вещественных алгебраических многообразий // Докл. РАН. 2008. Т. 420. № 4. С. 447-450.

212* Топология вещественных алгебраических кривых и интегрируемость геодезических потоков на алгебраических поверхностях // Функц. анализ и его приложения. 2008. Т. 42. Вып. 2. С. 23-27.

213. О неустойчивости равновесий консервативных систем при типичных вырождениях // Дифференц. уравн. 2008. Т. 44. № 8. С. 1033-1040.

214. Обобщенное кинетическое уравнение Власова // УМН. 2008. Т.63. Вып. 4. C. 53-90.

215* Several Problems on Dynamical Systems and Mechanics // Nonlinearity. 2008. Vol. 21. P. $149-155$.

216. Gauss Principle and Realization of Constraints // Regul. Chaotic Dyn. 2008. Vol. 13. No. 5. P. 431-434.

217. Принцип Гаусса и реализация связей // Нелинейная динамика. 2008. Т. 4. № 3. C. $281-285$.

2009 218. Теорема Кельвина о неустойчивости: топологический смысл и обобщения // Докл. РАН. 2009. Т. 424. № 2. С. 161-164.

219. Асимптотики решений сильно нелинейных систем дифференциальных уравнений. 2-е изд., исправленное и дополненное. М.-Ижевск: НИЦ «Регулярная и хаотическая динамика», Инст. компьютерн. иссл., 2009. 312 с. (совм. с С. Д. Фуртой).

220. Kinetics of Collisionless Gas: Equalization of Temperature, Growth of the Coarse-Grained Entropy and the Gibbs Paradox // Regul. Chaotic Dyn. 2009. Vol. 14. No. 4-5. P. 535-540.

221. Кинетика бесстолкновительного газа: выравнивание температуры, возрастание грубой энтропии и парадокс Гиббса // Нелинейная динамика. 2009. Т. 5. № 3. C. 377-383.

222. Релятивистская модель Пуанкаре // Докл. РАН. 2009. Т. 428. № 2. С. 171-176 (совм. с О. Г. Смоляновым).

223. О стабилизации равновесий периодическими по времени гироскопическими силами // Докл. РАН. 2009. Т. 429. №6. С. 762-763.

224. О механизме потери устойчивости // Дифференц. уравн. 2009. Т. 45. № 4. C. 496-505. 
2010 225. Избранные работы по математике, механике и математической физике. М.Ижевск: НИЦ «Регулярная и хаотическая динамика». 671 с.

226. Вариационный принцип для периодических траекторий обратимых уравнений динамики // Докл. РАН. 2010. Т. 430. № 5. С. 603-605.

227. Замечания о степени неустойчивости // ПММ. 2010. Т. 74. № 1. С. 18-21.

228. Спектральные свойства операторов с полиномиальными инвариантами в вещественных конечномерных пространствах // Тр. МИАН. 2010. Т. 268. С.155-167. 